\title{
Coincidence/Multiplicity Photofission Measurements
}

J. L. Jones

D. R. Norman

K. J. Haskell

M.T. Swinhoe

S. J. Tobin

W. H. Geist

R. B. Rothrock

C. R. Freeman

September 2009

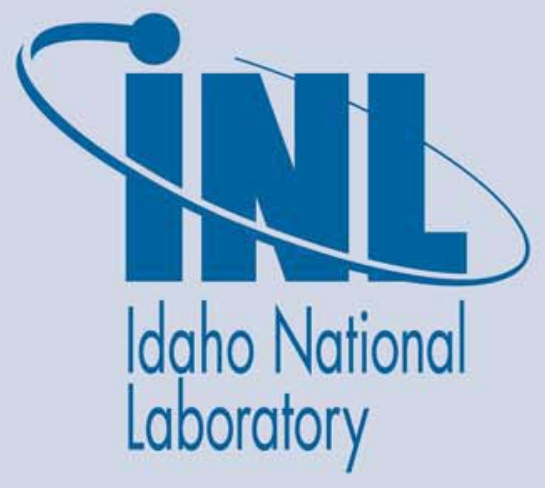

The INL is a U.S. Department of Energy National Laboratory operated by Battelle Energy Alliance 
INL/EXT-09-16971

\title{
Coincidence/Multiplicity Photofission Measurements
}

\author{
J. L. Jones \\ D. R. Norman \\ K. J. Haskell \\ M. T. Swinhoe ${ }^{1}$ \\ S. J. Tobin ${ }^{1}$ \\ W. H. Geist ${ }^{1}$ \\ R. Rothrock ${ }^{1}$ \\ C. R. Freeman ${ }^{1}$ \\ ${ }^{1}$ Los Alamos National Laboratory
}

September 2009

\section{Idaho National Laboratory Idaho Falls, Idaho 83415}

http://www.inl.gov

Prepared for the

U.S. Department of Energy

Office of National Nuclear Security Administration

Under DOE Idaho Operations Office

Contract DE-AC07-05ID14517 


\section{DISCLAIMER}

This information was prepared as an account of work sponsored by an agency of the U.S. Government. Neither the U.S. Government nor any agency thereof, nor any of their employees, makes any warranty, expressed or implied, or assumes any legal liability or responsibility for the accuracy, completeness, or usefulness, of any information, apparatus, product, or process disclosed, or represents that its use would not infringe privately owned rights. References herein to any specific commercial product, process, or service by trade name, trade mark, manufacturer, or otherwise, does not necessarily constitute or imply its endorsement, recommendation, or favoring by the U.S. Government or any agency thereof. The views and opinions of authors expressed herein do not necessarily state or reflect those of the U.S. Government or any agency thereof. 



\begin{abstract}
A series of experiments using the Idaho National Laboratory (INL) photonuclear inspection system and a Los Alamos National Laboratory (LANL) supplied, list-mode data acquisition method have shown enhanced performance utilizing pulsed photofission-induced, neutron coincidence counting between pulses of an up-to-10-MeV electron accelerator for nuclear material detection and identification. The enhanced inspection methodology has applicability to homeland security, treaty-related support, and weapon dismantlement applications. For the latter, this technology can directly support Department of Energy/NA241 programmatic mission objectives relative to future Rocky Ridgetype testing campaigns for active inspection systems.
\end{abstract}




\section{CONTENTS}

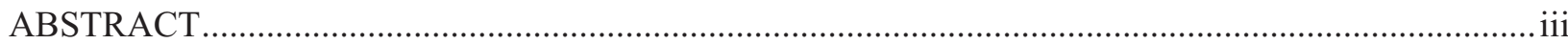

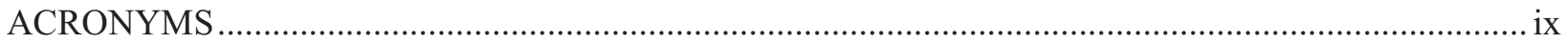

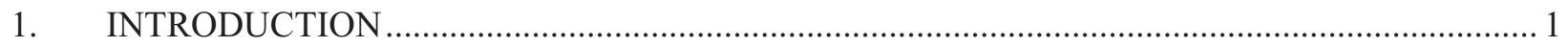

2. EXPERIMENTAL DESCRIPTION AND RESULTS .......................................................... 2

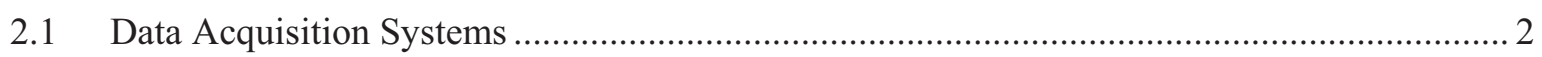

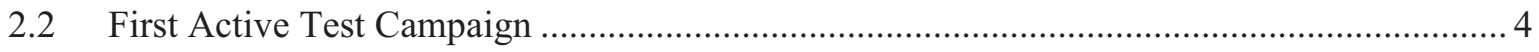

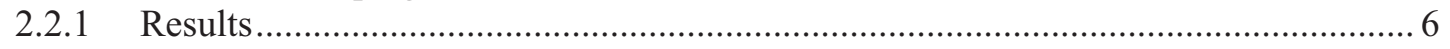

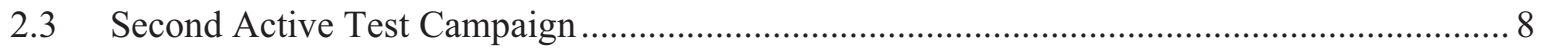

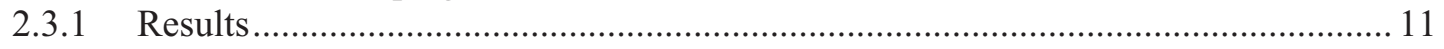

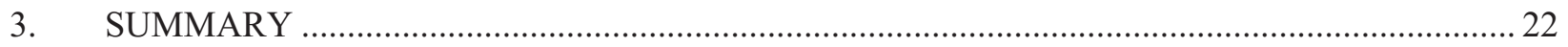

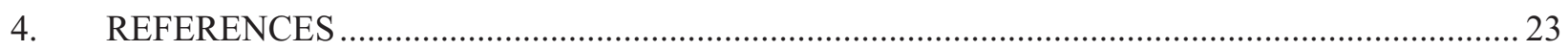

Appendix A List-mode Acquisition and Analysis ......................................................................... 24

\section{FIGURES}

Figure 2-1. The Photonuclear Neutron Detector (PND) . .................................................................... 2

Figure 2-2. The PND cosmic background suppression shroud (left) and several PNDs with

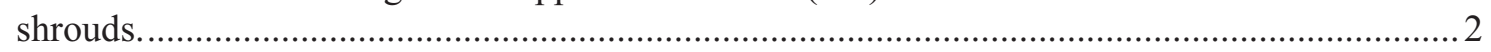

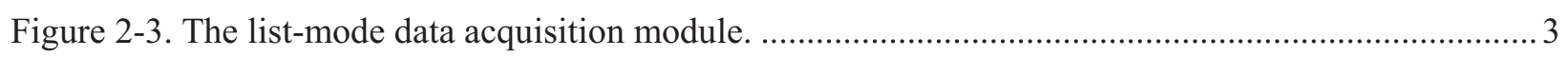

Figure 2-4. Converter box used to convert TTL signals from the PNDs into a differential signal

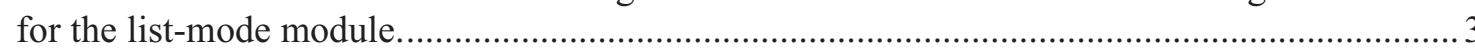

Figure 2-5. Experimental setup of the Varitron accelerator, the multiple PNDs positioned downstream of the accelerator, and the aluminum sample holder between two rows of PNDs.

Figure 2-6. HEU, stainless steel, and DU targets (left to right). (Note, aluminum bricks were used to align the targets with the beam axis when no additional moderator material was added.)

Figure 2-7. Polyethylene moderator sandwich configuration around DU.

Figure 2-8. The selected polyethylene and bismuth composite shield configuration. (Nuclear material is sandwiched between slabs of $2.5 \mathrm{~cm}$-thick bismuth and segments of $5.1 \mathrm{~cm}$-square polyethylene.)

Figure 2-9. HEU-drum irradiation configuration. (Drum is centered on beam axis and its nearest

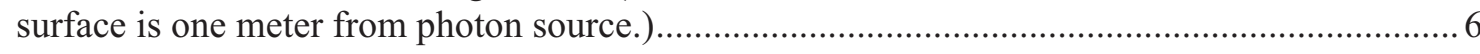

Figure 2-10. Data for example cases collected with list-mode electronics.......................................... 8

Figure 2-11. FY09 test configurations showing the INL Varitron and the detector configuration...............9 
Figure 2-12. A schematic of the actual detector layout.

Figure 2-13. Calibration testing with the ${ }^{252} \mathrm{Cf}$ sources. (Note the $1-\mathrm{m}$ red alignment lasers on the

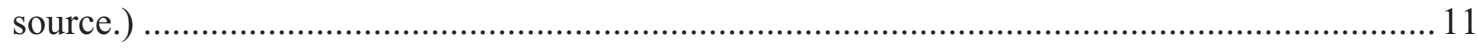

Figure 2-14. The Pu source. (Note 1-m red alignment lasers on lower housing in left picture)............... 11

Figure 2-15. Counting rate for each detector with the $\mathrm{Pu}$ and $\mathrm{Cf}$ sources. ............................................ 13

Figure 2-16. DU (left) and HEU (with stainless steel cladding) used in FY-09 assessments.................... 14

Figure 2-17. A typical shield configuration with the nuclear material positioned at $1.1-\mathrm{m}$ from the

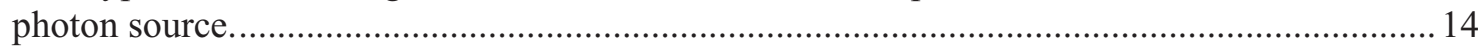

Figure 2-18. Doubles and Singles counting rates from different inspected objects for an 8-MeV

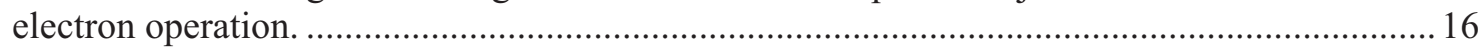

Figure 2-19. Doubles and Singles counting rates from different inspected objects for a $10-\mathrm{MeV}$

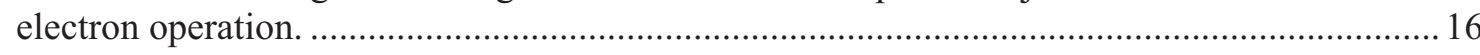

Figure 2-20. Shielded and unshielded HEU and DU results from PND 3 for a 4-8 ms acquisition window.

Figure 2-21. Singles count rates for shielded and unshielded HEU and DU results from list-mode

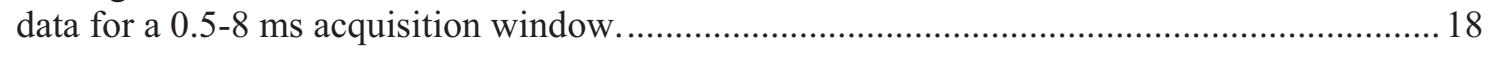

Figure 2-22. Doubles count rates for shielded and unshielded HEU and DU results from list-mode

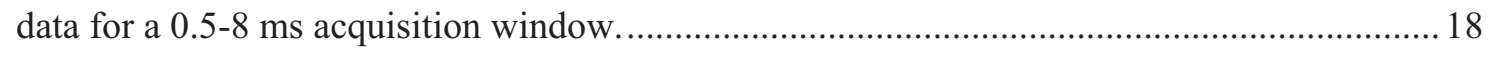

Figure 2-23. Doubles/Singles ratio for shielded and unshielded HEU and DU results from list-

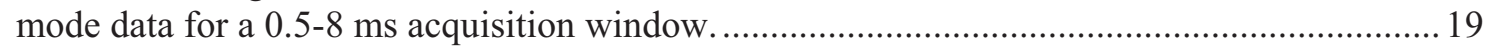

Figure 2-24. PND 3 Singles response for HEU with various thicknesses of DU. .................................. 19

Figure 2-25. Maximum DU shield thickness for the two HEU plates (at nominal 1-m inspection position). The interrogating beam is incident normally on the DU with the accelerator to the left of the observer's position. For each thickness, DU is similarly configured on the front and back.

Figure 2-26. List-mode data for HEU with various thicknesses of DU. (Left figure shows Singles.

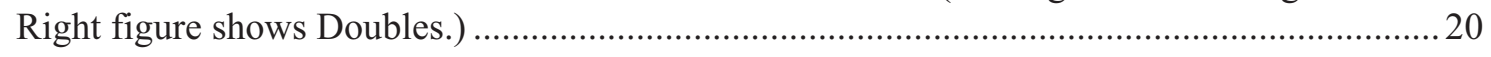

Figure 2-27. Doubles/Singles ratio from list-mode data for HEU with various thicknesses of DU..........21

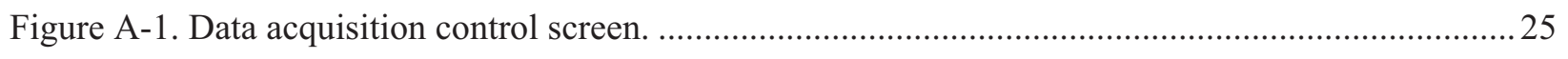

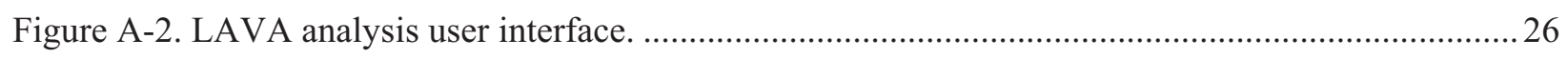

Figure A-3a. Count rate after the accelerator pulse (time in seconds) .................................................. 26

Figure A-3b. Count rate after the accelerator pulse - magnified time scale (time in seconds). ................27

Figure A-4. Count rate as a function of time (over 10 minutes)...........................................................2 27

\section{TABLES}

Table 2-1. First Test Campaign Data Analysis (all statistical error within $\pm 4 \%$ ) ................................... 7

Table 2-2. Selective PND results for ${ }^{252} \mathrm{Cf}$ and $\mathrm{Pu}$ sources at the nominal 1-m interrogation position using 120-s acquisitions with a 4-ms start acquisition window. (Includes natural background.). 
Table 2-3. List-mode multiplicity results for ${ }^{252} \mathrm{Cf}$ and $\mathrm{Pu}$ source at the nominal $1-\mathrm{m}$ interrogation position using 120-s acquisitions. (Includes natural background.).

Table 2-4. Accelerator $\mathrm{ON}$ results at 1-m interrogation position........................................................... 15 


\section{ACRONYMS}

AIM Acquisition Interface Module

DU depleted uranium

HEU highly enriched uranium

INL Idaho National Laboratory

LANL Los Alamos National Laboratory

LINAC linear accelerator

MCS Multi-channel Scaler

PC personal computer

PND Photonuclear Neutron Detector

TTL transistor-transistor logic 


\section{Coincidence/Multiplicity Photofission Measurements 1. INTRODUCTION}

As early as FY-08, efforts began in assessing the potential advantages of using a LANL list-mode data acquisition system ${ }^{1}$ with multiple INL Photonuclear Neutron Detectors (PNDs) ${ }^{2}$ and the INL transportable, selectable-energy (up to a nominal $10 \mathrm{MeV}$ ), pulsed linear electron accelerator ${ }^{3}$ (that is, the Varitron). The objective was to assess time-correlated, photofission delayed neutron measurements between accelerator pulses and compare with INL measurements. An initial passive scoping test in August 2007 showed basic feasibility of using the INL PNDs for coincident counting and the potential for enhancing the INL active photonuclear inspection system. The first active test campaign was conducted at INL during April 21-24, 2008, using a nominal 8-MeV, 125-Hz electron beam operation with a $\sim 10 \mu \mathrm{A}$ average beam current. This first campaign focused on the detection of induced delayed neutrons between each $4 \mu$ s-wide accelerator pulse. After each accelerator trigger pulse, the data acquisition windows started at $1.9 \mathrm{~ms}$ for the INL acquisitions and $400 \mu \mathrm{s}$ for the LANL acquisitions and extended to the next accelerator electron pulse. While higher (up to $\sim 10 \mathrm{MeV}$ ) and lower (down to $\sim 3 \mathrm{MeV}$ ) nominal energies were possible with this accelerator, the $8-\mathrm{MeV}$ operation was selected for the first-year assessment since it represented a typical high-energy radiographic device. A second follow-on test campaign was conducted at INL in May 2009 assessing an enhanced LANL-built, list-mode acquisition system fabricated for INL, studied system detection/identification performance utilizing up to nominal $10-\mathrm{MeV}$ electron beam operations, and provided additional inspection object characterization data. The following sections describe the two active inspection campaigns and their results that continue to show overall system feasibility and enhanced inspection performance. 


\section{EXPERIMENTAL DESCRIPTION AND RESULTS}

This section describes the data acquisition systems, the experimental configurations and the results of two testing campaigns conducted to assess the integration of a list-mode, coincidence neutron counting method with a nuclear material detection technique utilizing energetic photon interrogation.

\subsection{Data Acquisition Systems}

The INL detection system consists of multiple PNDs (see Figure 2-1) providing transistor-transistor logic(TTL)-type signals to a Nuclear Data/Canberra 578 Multi-channel Scaler (MCS) module that provides data to a Canberra Genie 2000 acquisition analysis software via a Canberra 556 Acquisition Interface Module (AIM). The system has a data throughput of up to $\sim 500 \mathrm{kHz}$. A 16$\mathrm{kg}$ PND is $117-\mathrm{cm}$ long with an outer 10.16-cm diameter aluminum housing. The detector contains an internal high-voltage power supply, an INL-built fast preamplifier, and a 10-atm., $2.54-\mathrm{cm}$ diameter, ${ }^{3} \mathrm{He}$ tube surrounded by concentric rings of polyethylene moderator, cadmium metal, and $\sim 25 \%$ boron-loaded, flexible shielding. This physical shielding configuration enables the selective detection of $\sim 0.1-\mathrm{keV}$ to $\sim 2 \mathrm{-MeV}$ neutrons, while temporal selectivity enables fission-delayed neutron detection. To help suppress energetic cosmic neutron background contributions, a $\sim 12.5-\mathrm{kg}, 15.2-\mathrm{cm}$ wide, $12.7-\mathrm{cm}$ deep, $127-\mathrm{cm}$ tall polyethylene shroud can enclose a PND as shown in Figure 2-2 (shown without the standard $2.5-\mathrm{cm}$ thick endcaps). For these assessments, the MCS operated with up to eight detector inputs, each with 512 temporal

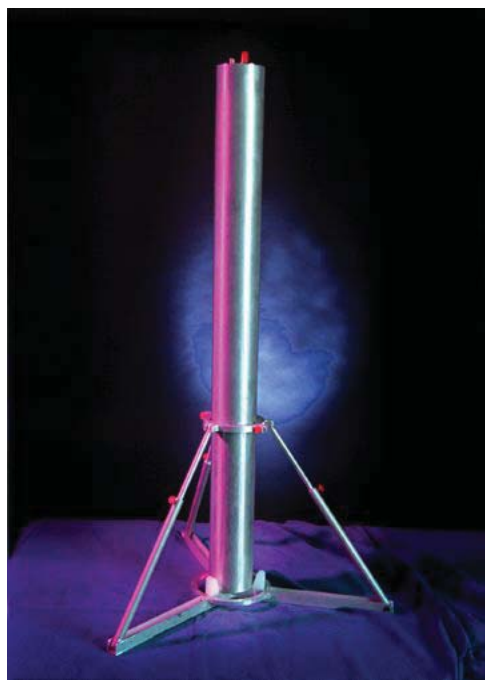

Figure 2-1. The Photonuclear Neutron Detector (PND). channels (with the first channel assigned to be the trigger-counting channel). Each MCS channel was $15 \mu$ s-wide (resulting in 7.67-ms sweeps per trigger pulse), to correspond to the maximum $125-\mathrm{Hz}$ accelerator operation, resulting in a total of $8 \mathrm{~ms}$ between each trigger signal.
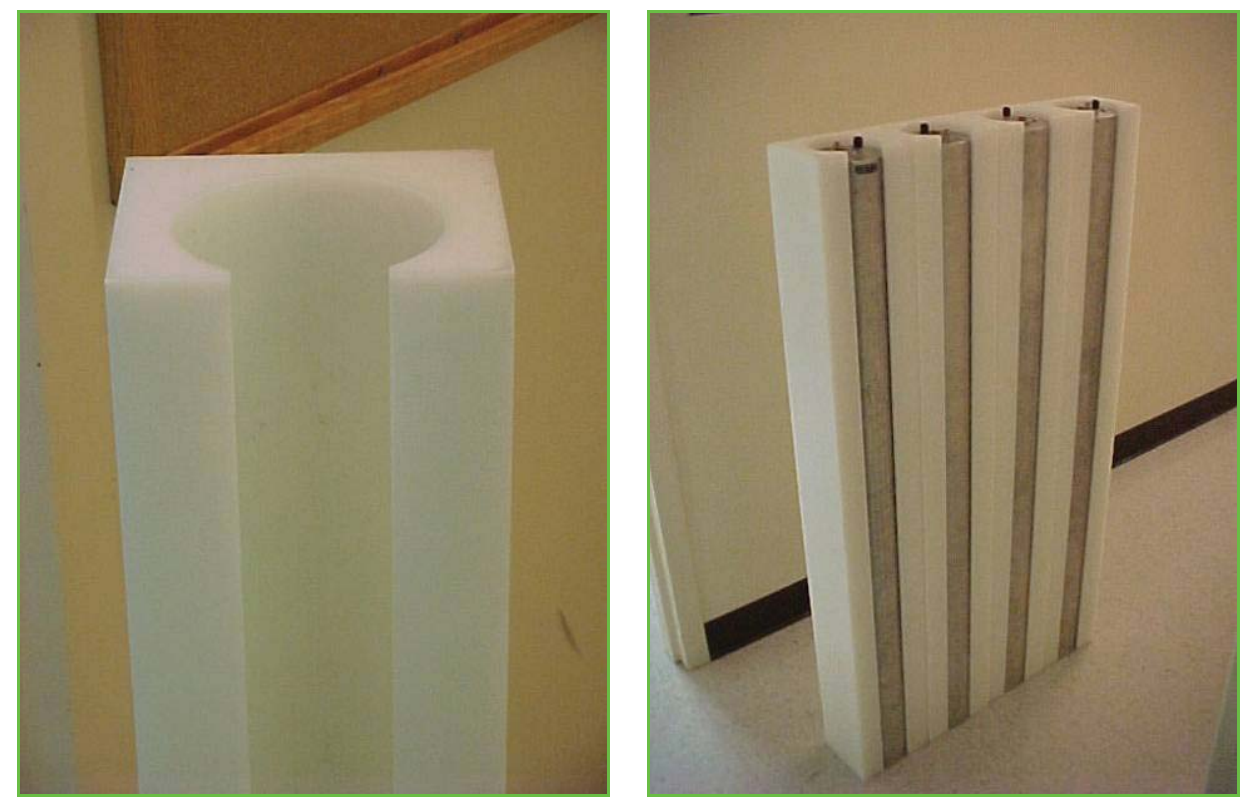

Figure 2-2. The PND cosmic background suppression shroud (left) and several PNDs with shrouds. 
The LANL data acquisition is based on a list-mode module that records the time of arrival of every pulse using up to 32 channels of data (Figure 2-3). The highest channel is used to record accelerator trigger pulses. The data are transferred to a personal computer (PC) via an Ethernet connection. The TTL signals from the PND detectors are converted to differential signals on a pair of ribbon cables using a converter box (Figure 2-4). Both the list-mode module and the converter box require 5V power supplies.

An acquisition program runs on the $\mathrm{PC}$ to receive the data packets from the list-mode module. This program stores the data on the PC in a binary file. This file consists of a simple list of pulse arrival times and channels. The data in each file are analyzed by a custom-designed program that allows the user to specify the desired data analysis parameters. (More detail is given in Appendix A).

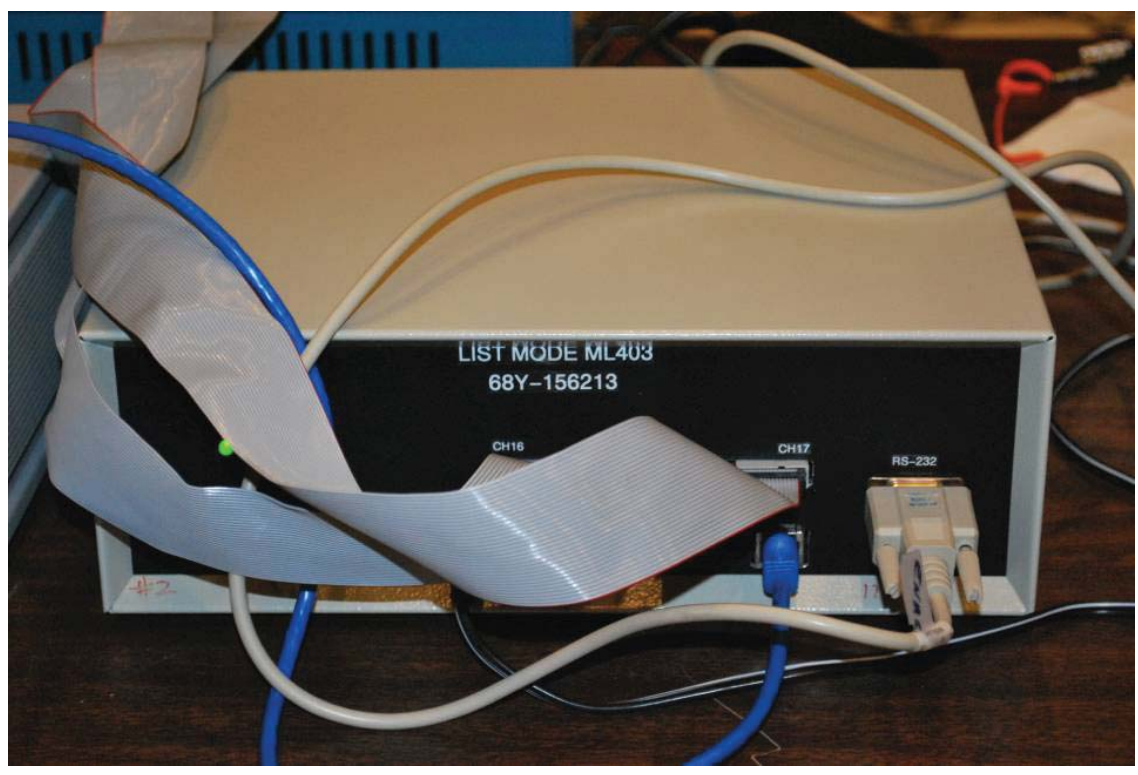

Figure 2-3. The list-mode data acquisition module.

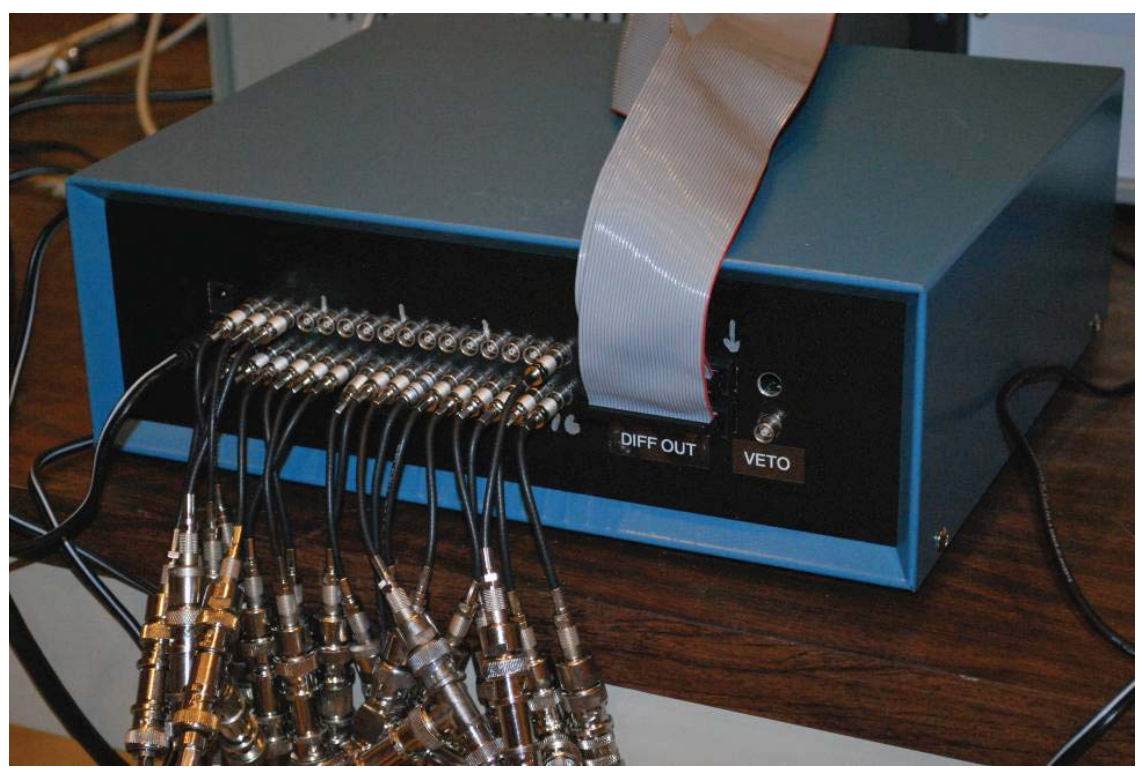

Figure 2-4. Converter box used to convert TTL signals from the PNDs into a differential signal for the list-mode module. 


\subsection{First Active Test Campaign}

Figure 2-5 shows the experimental configuration of the first campaign using an array of 20 vertically-positioned PND detectors with their polyethylene cosmic-radiation-suppression shrouds. All detectors were positioned within two meters forward of the accelerator's bremsstrahlung photon source, and their output signals were connected to both the INL and LANL data acquisition systems. An aluminum holder assembly was used for positioning of the inspection objects.

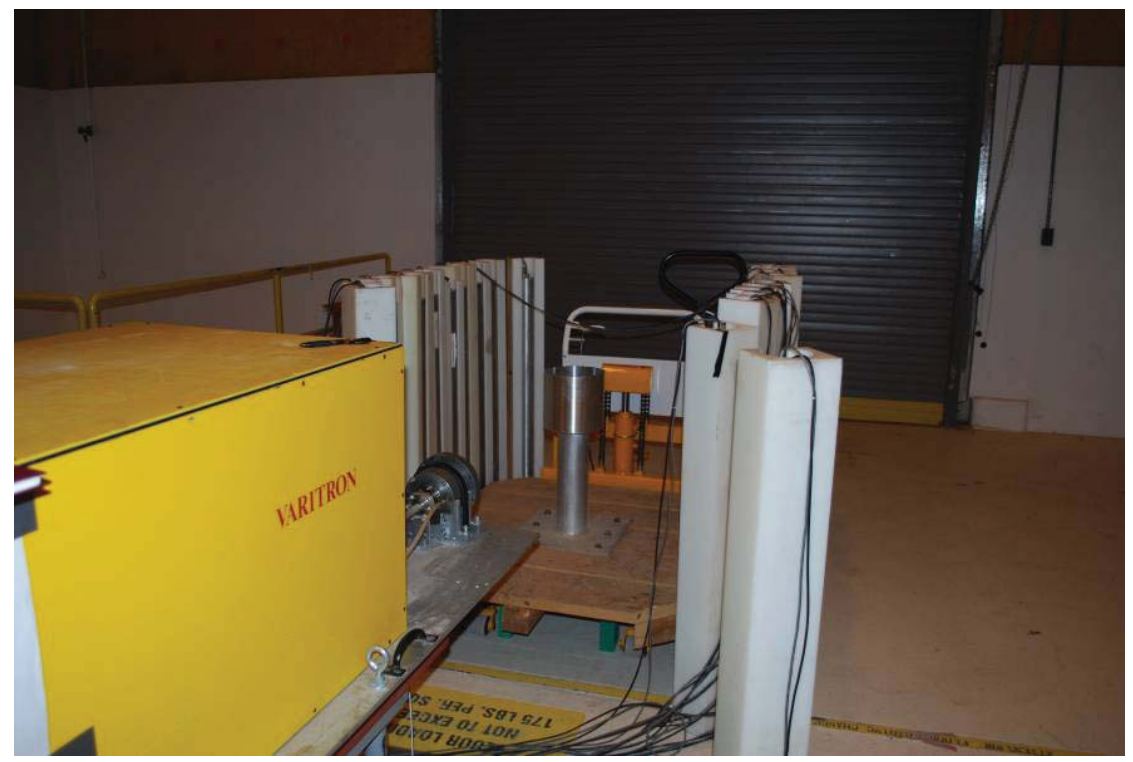

Figure 2-5. Experimental setup of the Varitron accelerator, the multiple PNDs positioned downstream of the accelerator, and the aluminum sample holder between two rows of PNDs.

The specific inspected-object location selected for these tests is the center of an aluminum holder defined by a $20.3-\mathrm{cm}$ tall, $20.3-\mathrm{cm}$ diameter, $1.3-\mathrm{cm}$ thick holder centered on the beam axis and having its outer surface located $1 \mathrm{~m}$ from the accelerator's photon (bremsstrahlung) source. Hence, a test object placed within the holder configuration will have a nominal 110-cm source-to-inspection object distance.

Two parallel sets of 10 PND detectors (total of 152-cm wide, 13-cm deep, and 127-cm tall), centered with the vertical mid-plane of the holder, have their front surfaces placed at $\sim 56 \mathrm{~cm}$ on either side of the electron beam centerline. Hence, the center two PNDs of each parallel detector bank are located about $\sim 56 \mathrm{~cm}$ from the sample location, while the surface of the end-most PNDs (or assembly "edge" detectors) is about $100 \mathrm{~cm}$ from a test object. For these tests, the Varitron uses a \pm 30 degree photon collimator to assure complete irradiation with the nominal $8-\mathrm{MeV}$ bremsstrahlung radiation for any object placed at the defined inspection location.

The main inspection objects assessed in these tests are shown in Figure 2-6. They include a non-nuclear material (two stainless-steel plates [5.1 $\times 15.2 \times 0.3-\mathrm{cm} ; 186 \mathrm{~g}$ each]) and two nuclear materials (two 93.3\% highly enriched uranium (HEU) metal plates [5.1 $\times 10.2 \times 0.3-\mathrm{cm}$ : $288 \mathrm{~g}$ each, 576 $\mathrm{g}$ total] and a single $10.4 \times 10.4 \times 0.3-\mathrm{cm}$; depleted uranium (DU) metal plate $[605 \mathrm{~g}])$. Each target was assessed with and without a moderator sandwich of polyethylene (see Figure 2-7) that consisted of multiple $5.1-\mathrm{cm}$-square segments $20.3-\mathrm{cm}$ long. To address composite shielding issues, additional tests (see Figure 2-8) included the HEU target sample sandwiched between slabs $(15.2 \times 20.3 \times 2.5-\mathrm{cm})$ of high-Z shielding (that is, bismuth) and 5.1-cm-square polyethylene segments. 


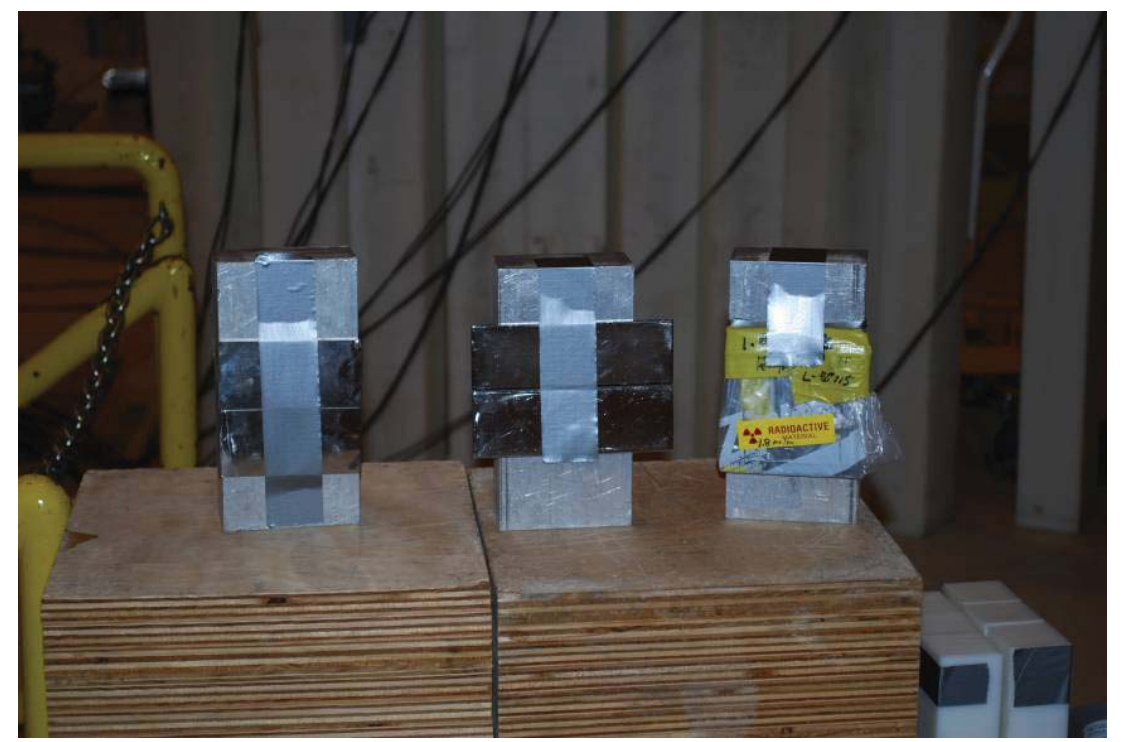

Figure 2-6. HEU, stainless-steel, and DU targets (left to right). (Note, aluminum bricks were used to align the targets with the beam axis when no additional moderator material was added.)

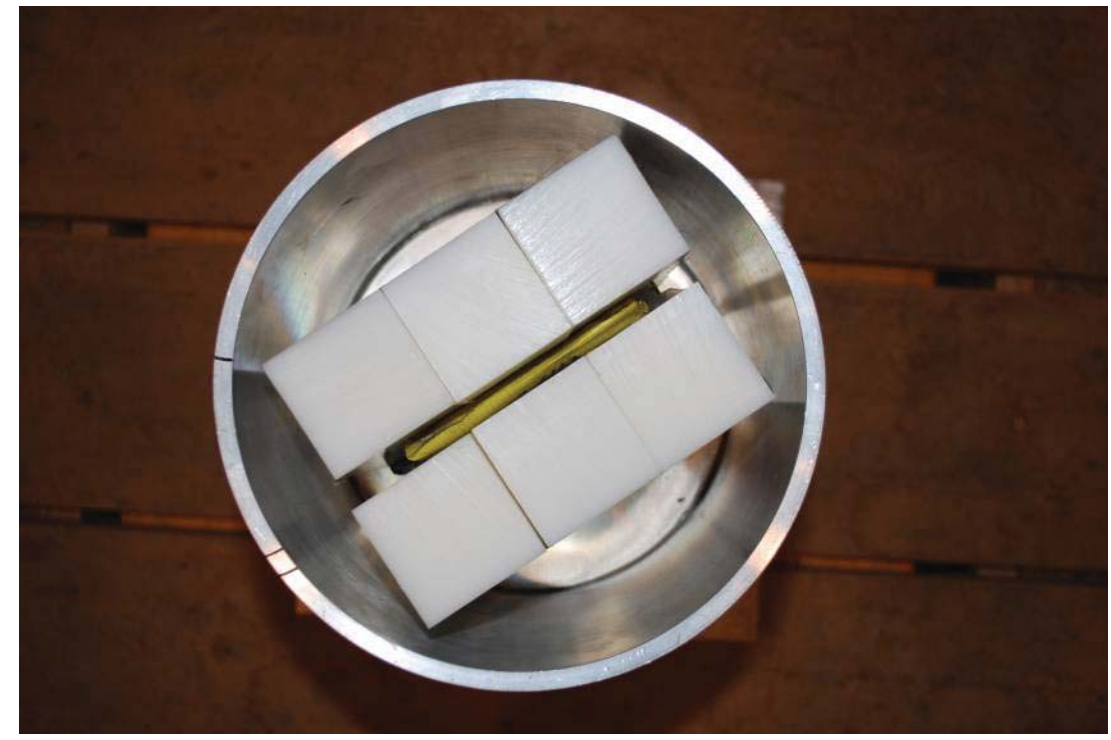

Figure 2-7. Polyethylene moderator sandwich configuration around DU. 


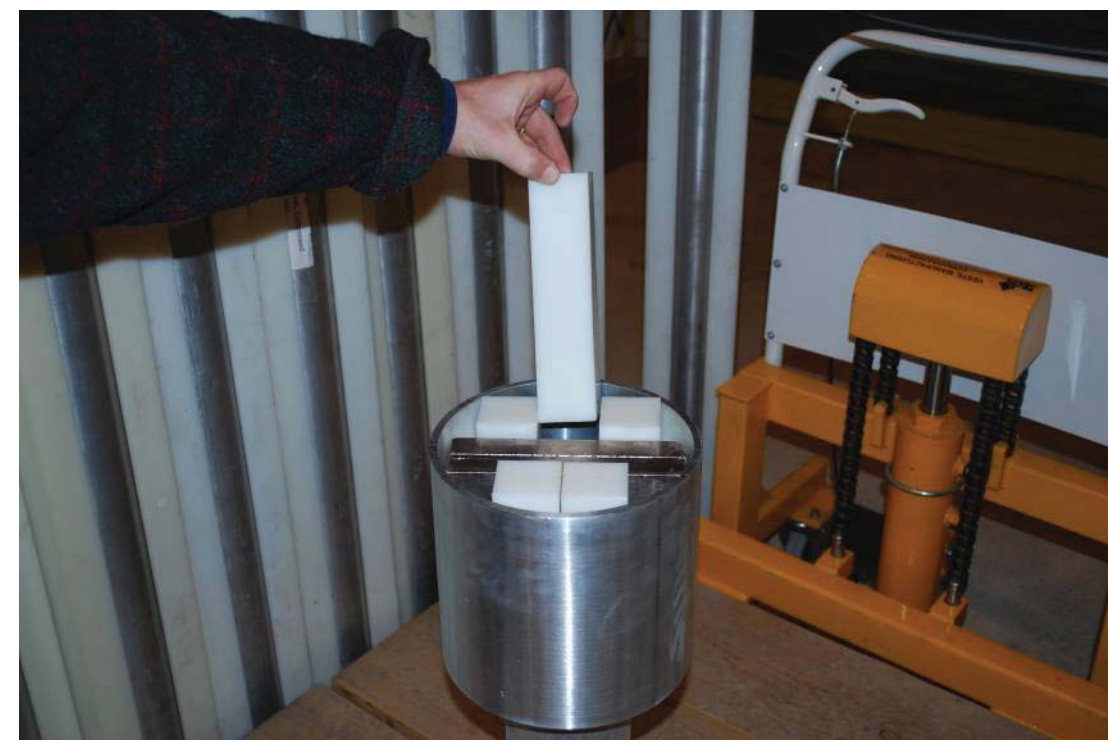

Figure 2-8. The selected polyethylene and bismuth composite shield configuration. (Nuclear material is sandwiched between slabs of $2.5 \mathrm{~cm}$-thick bismuth and segments of $5.1 \mathrm{~cm}$-square polyethylene.)

An additional assessment included a 55-gallon drum (standard Department of Transportation-6M) filled with $7.9 \mathrm{~kg}$ of ${ }^{235} \mathrm{U}$ (unirradiated oxide fuel pins of $46 \%{ }^{235} \mathrm{U}$ ). As shown in Figure 2-9, the surface of the upright-positioned drum was positioned at one meter from the bremsstrahlung source and centered on the beam axis.

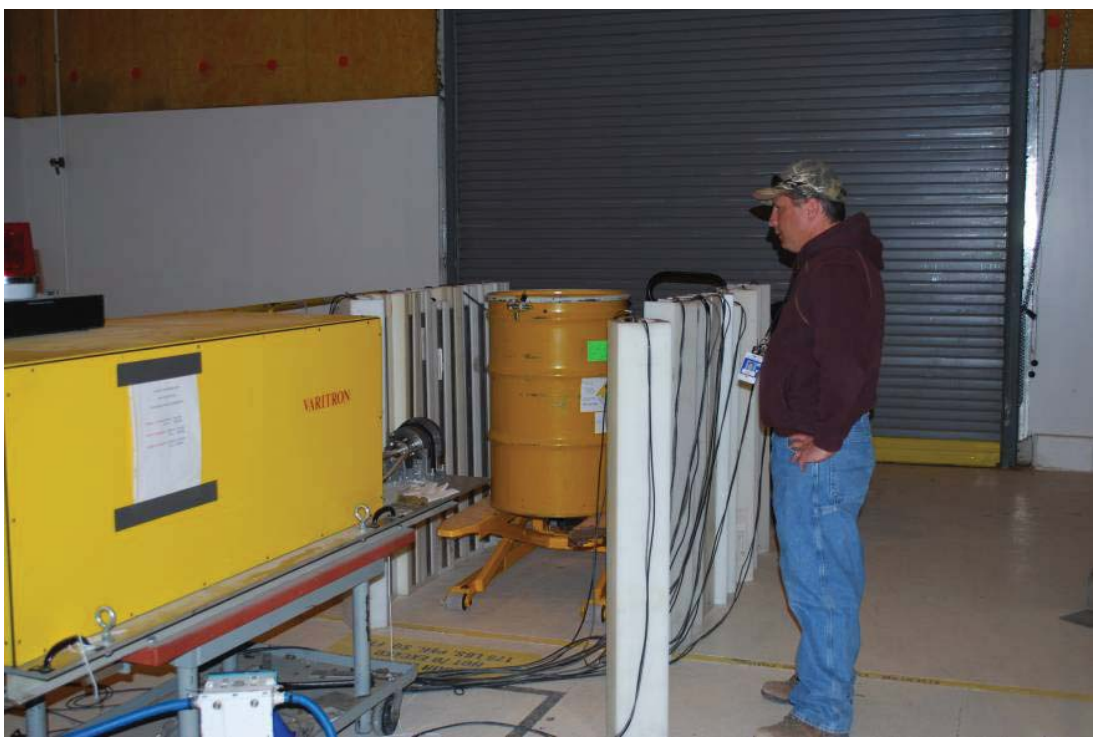

Figure 2-9. HEU-drum irradiation configuration. (Drum is centered on beam axis and its nearest surface is $1 \mathrm{~m}$ from photon source.)

\subsubsection{Results}

Table 2-1 presents a summary of the various cases studied in this first experimental assessment using a nominal 8-MeV accelerator operation. In all cases that used nuclear material, the error in the Singles data is less than $\pm 4 \%$ and additional data collection time would have been needed to provide a similar error for other data collected (for example, Doubles, Triples, backgrounds). A ${ }^{252} \mathrm{Cf}$ source $\left(5.4 \times 10^{4} \mathrm{n} / \mathrm{s}\right.$ : $540 \mu \mathrm{Ci}$ as of 1/94) was used for system calibration. The list-mode data from two PNDs in the 20-PND 
configuration were not utilized because of observed signal oscillation problems; hence, the list-mode data acquisition utilized 18 PNDs and considered a larger acquisition window. Double neutron coincident counting was measured, and in some cases, triple neutron coincidences were observed!

Some of the collected PND and list-mode data are shown in Figure 2-10 and presented in Table 2-1. Using the calculated ${ }^{252} \mathrm{C}$ f source strength and the detector's ${ }^{252} \mathrm{Cf}$ calibration performance of $\sim 3 \mathrm{E}-4$ counts/source neutron at one meter (from a prior assessment ${ }^{2}$ ), it was estimated that a PND at $1 \mathrm{~m}$ should provide about 16.2 counts/s or about 12.4 counts/s in a 1.9-8-ms acquisition window between trigger pulses. The right bank edge detector showed $10.8 \pm 0.3$ counts per second after being corrected for a $0.8 \pm 0.08 \mathrm{count} / \mathrm{s}$ background. Based on the measurement uncertainties of the physical test configuration used during the source tests, the potential source strength uncertainty, and the estimated calibration performance value, the yield response and the measured response compared well. (Another calibration is performed in Section 2.3.1.)

Table 2-1. First test campaign data analysis (all statistical error within $\pm 4 \%$ )

\begin{tabular}{|c|c|c|c|c|}
\hline Case & $\begin{array}{l}\text { Net Singles } \\
\mathrm{INL}^{1}(\mathrm{cts} / \mathrm{s})\end{array}$ & $\begin{array}{c}\text { Singles LANL }{ }^{2} \\
(\mathrm{cts} / \mathrm{s})\end{array}$ & $\begin{array}{c}\text { Doubles LANL } \\
(\mathrm{cts} / \mathrm{s})\end{array}$ & $\begin{array}{c}\text { Doubles/Singles } \\
\text { Ratio } \\
\end{array}$ \\
\hline${ }^{252} \mathrm{Cf}$ & 10.8 & 367 & 2.8 & 0.0076 \\
\hline DU w/o poly & 19.0 & 851 & 4.9 & 0.0057 \\
\hline HEU w/o poly & 15.7 & 757 & 8.7 & 0.012 \\
\hline DU w/poly & 8.8 & 368 & 3.3 & 0.0089 \\
\hline HEU w/poly & 17.5 & 749 & 35.1 & 0.047 \\
\hline Poly & 0.9 & 51.3 & 0.9 & 0.018 \\
\hline HEU w/Bi \& Poly & 19.1 & 787 & 90.3 & 0.11 \\
\hline w/Bi \& Poly & 0.0 & 174 & 1.4 & 0.0079 \\
\hline $7.9 \mathrm{~kg}^{235} \mathrm{U}$ (DRUM) & 128 & $2614^{3}$ & $243^{3}$ & $0.093^{3}$ \\
\hline \multicolumn{5}{|c|}{$\begin{array}{l}\text { 1. Single PND net counts at one meter from sample location ( } 1.9 \mathrm{~ms} \text { start time). } \\
\text { 2. Multiple (18) PNDs } \leq 1 \mathrm{~m} \text { from sample ( } 400 \mu \mathrm{s} \text { start time). } \\
\text { 3. Multiple (18) PNDs } \leq 1 \mathrm{~m} \text { from sample ( } 3 \mathrm{~ms} \text { start time). }\end{array}$} \\
\hline
\end{tabular}

Figure 2-10 shows that the delayed neutron period starts about $1 \mathrm{~ms}$ after the pulse for the small samples and about $3 \mathrm{~ms}$ after the accelerator's trigger pulse in the case of the drum (mainly due to the large amount of ${ }^{235} \mathrm{U}$ and the related differential die-away). Table 2-1 results show that the Singles counting rate is a clear indication of the presence of nuclear material (HEU or DU). Note, DU gives more delayed neutrons per gram than ${ }^{235} \mathrm{U}$ and the Singles signal is proportional to the mass (if self-shielding effects are minimal). On the other hand, the Doubles are a clear indication of fissile material rather than just nuclear material. This is true even when the fissile material is shielded with high- $Z$ gamma and/or low-Z neutron shielding. 


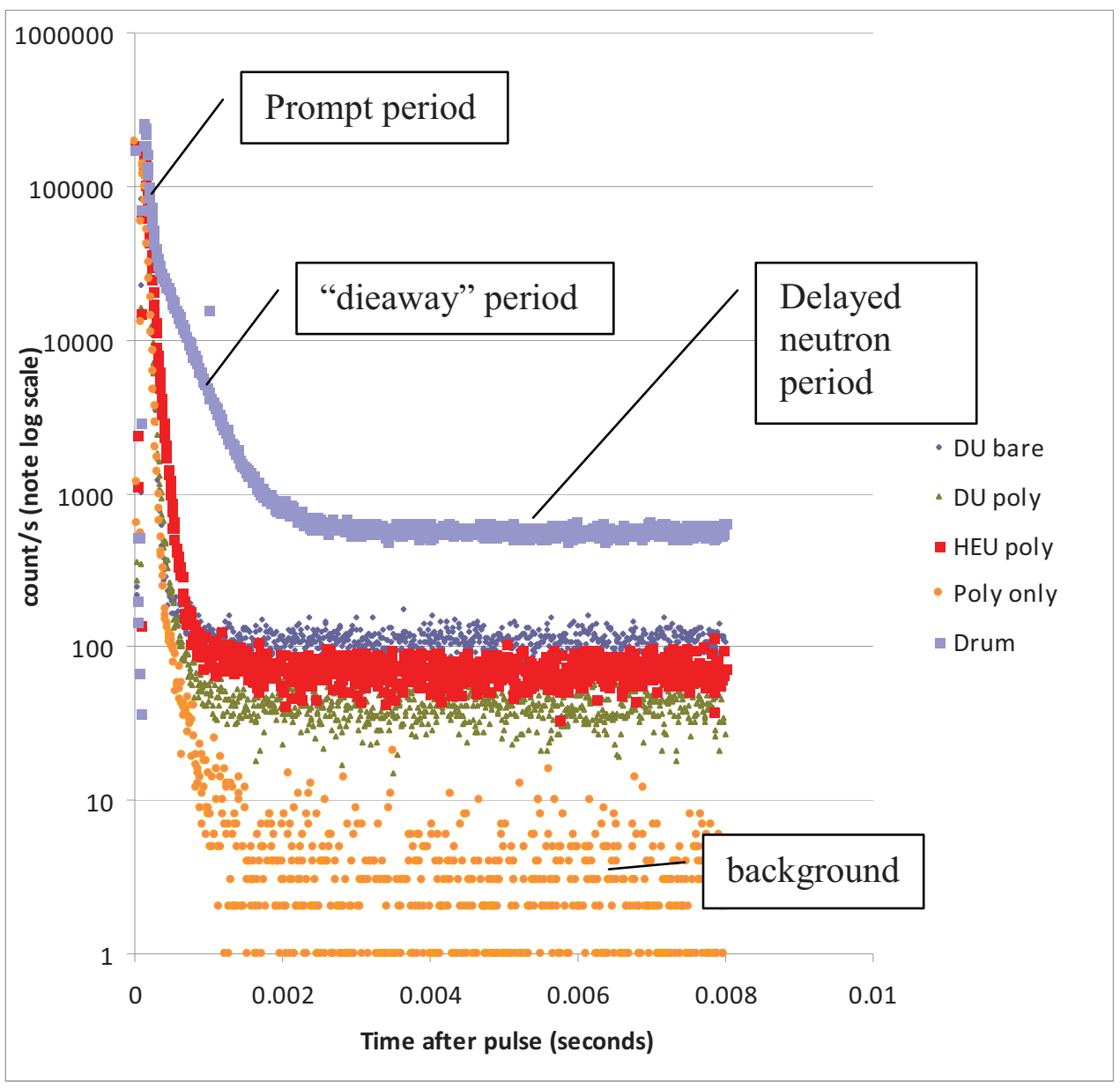

Figure 2-10. Data for example cases collected with list-mode electronics.

The "Poly" case is representative of all non-nuclear material backgrounds. For example, without nuclear material, the total PND single response shows $\sim 0.9$ counts/s, and $\sim 0$ net counts/s for "Poly" and "w/Bi and Poly" respectively, and is essentially independent of the 8-MeV accelerator operation. In general, the single INL detector data and LANL Singles data compare quite well if one realizes that the LANL data are based on an overall 18-PND configuration with each PND located at less than $1 \mathrm{~m}$ from the sample locations; whereas the single PND detector used in the INL acquisition corresponded to a 1-m inspected object-to-detector position. The only notable comparison exception is the INL and LANL Singles data for the "w/Bi \& Poly" case; which is an artifact of the very low non-nuclear material count rate and its increased relative error for a single detector. In addition, the LANL acquisition window, starting at $0.4 \mu \mathrm{s}$, includes a small portion of the prompt photoneutron die-away from the photon pulse, which especially affects the comparison when there is a low count rate in the delayed region.

\subsection{Second Active Test Campaign}

The second test campaign was performed with a different PND detector configuration. This experimental detector configuration is shown in Figure 2-11. This configuration has a narrower detector bank-to-bank separation distance and attempts to maximize a $4 \pi$-type neutron emission detection. These tests used 18-PND detectors as before, but with a different layout schematically shown in Figure 2-12. The new configuration employed three banks of six PND detectors (with background suppression 
shrouds). Due to a structural support, the top bank of detectors is positioned about $2 \mathrm{~cm}$ above the vertically positioned detector shrouds (without a $2.5-\mathrm{cm}$ thick polyethylene endcap).

This campaign used the INL and LANL-built acquisition systems that were used in the first campaign. While a second list-mode acquisition module was assembled for INL having nearly ten times more data throughput capability, the initial operational assessment of the new module showed problems with its trigger pulse registration. After realizing that the higher throughput were not as beneficial as earlier thought due to limitations of the PND's signal timing and the fact that the original module was operating satisfactorily, we collectively decided to continue using the original module.

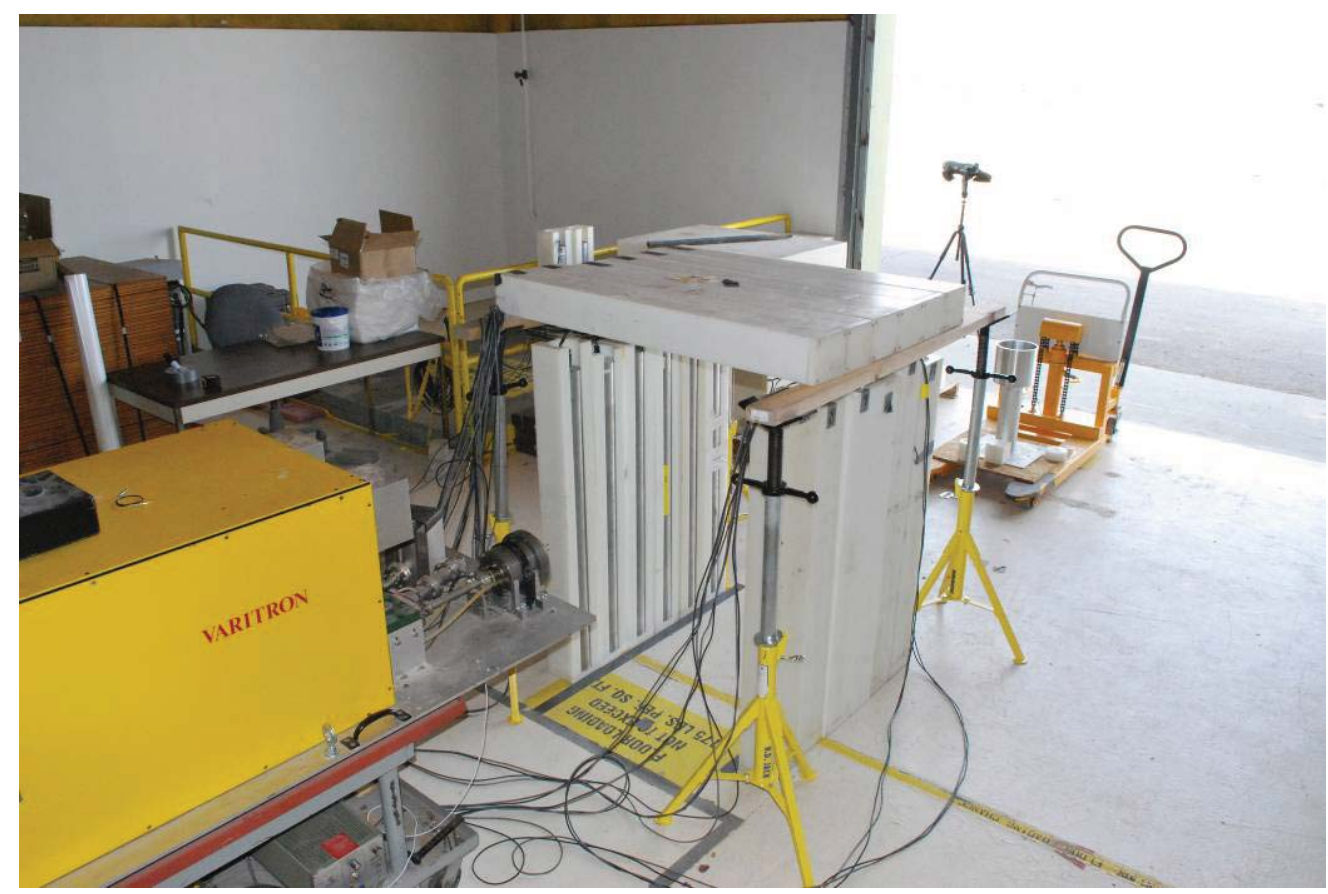

Figure 2-11. FY09 test configurations showing the INL Varitron and the detector configuration. 


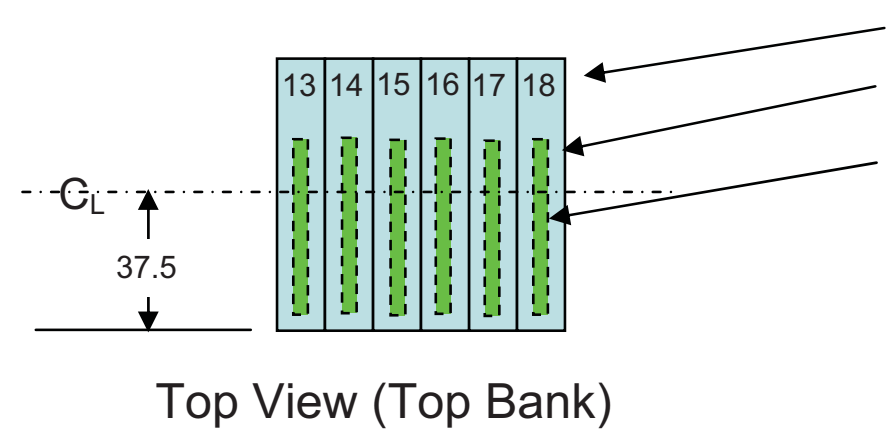

Detector Numbers

Background Suppression Shroud

10-Atm., 2.5-cm dia, He-3 Tube

(All dimensions in centimeters)
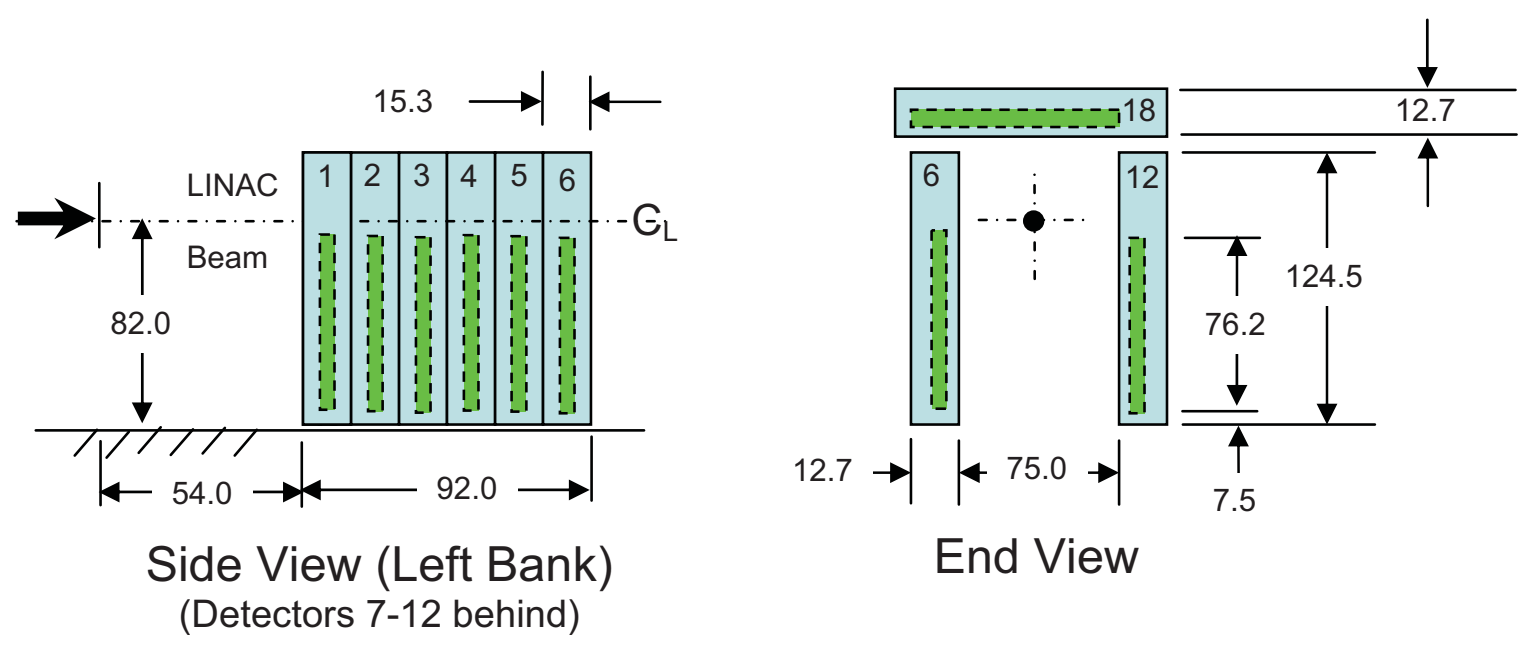

Figure 2-12. A schematic of the actual detector layout.

For each test, the inspected object was positioned within the detector "cave" on the electron beam axis (82-cm from the ground) and $1 \mathrm{~m}$ from the electron/bremsstrahlung converter (that is, the photon source). With this configuration, Detectors 15 and 16 in the Top Bank, Detectors 3 and 4 in the Left Bank (relative to the End View), and Detectors 9 and 10 in the Right Bank were the closest to the 1-m inspection position; with the closest distances being 45.5, 37.5, and $37.5 \mathrm{~cm}$, respectively. As presented in Figure 2-12, the actual ${ }^{3} \mathrm{He}$ tubes are below the beam centerline for both Left and Right Bank detectors with closest tubes located in the Top Bank detectors.

All the PND detectors were input and assessed with the LANL acquisition system, while only selective PND detectors were acquired with the INL acquisition system. Relative to the latter, the selected detectors included the outermost "End View" detectors $(6,12$, and 18), and the centermost detectors (3, 9 and 15).

The first tests involved a ${ }^{252} \mathrm{Cf}$ and $\mathrm{Pu}$ calibration assessment. The ${ }^{252} \mathrm{Cf}$ assessment consisted of two small-yield point sources $\left(\sim 4.2 \times 10^{4} \mathrm{n} / \mathrm{s}\right.$ each; April 2009) positioned at the nominal 1-m position (as shown in Figure 2-13 hanging from the string from the Top Bank detectors) and the Pu source was a $175.7 \mathrm{~g}$ source (with $166.7 \mathrm{~g}$ of ${ }^{239} \mathrm{Pu}$ and $8 \%{ }^{240} \mathrm{Pu}$ ) resulting in a yield of about $2-3 \times 10^{4} \mathrm{n} / \mathrm{s}$ (about one-third of the total californium yield.) The Pu source was encased in a $\sim 30-\mathrm{cm}$ long, $\sim 7.6$-cm diameter, $\sim 0.76-\mathrm{cm}$ thick stainless-steel housing, as shown in Figure 2-14. During the Pu source calibrations, the exact source alignment with the beam and the outer housing (see the laser alignment in Figure 2-14) was unknown since the source appeared to move freely within the housing. 


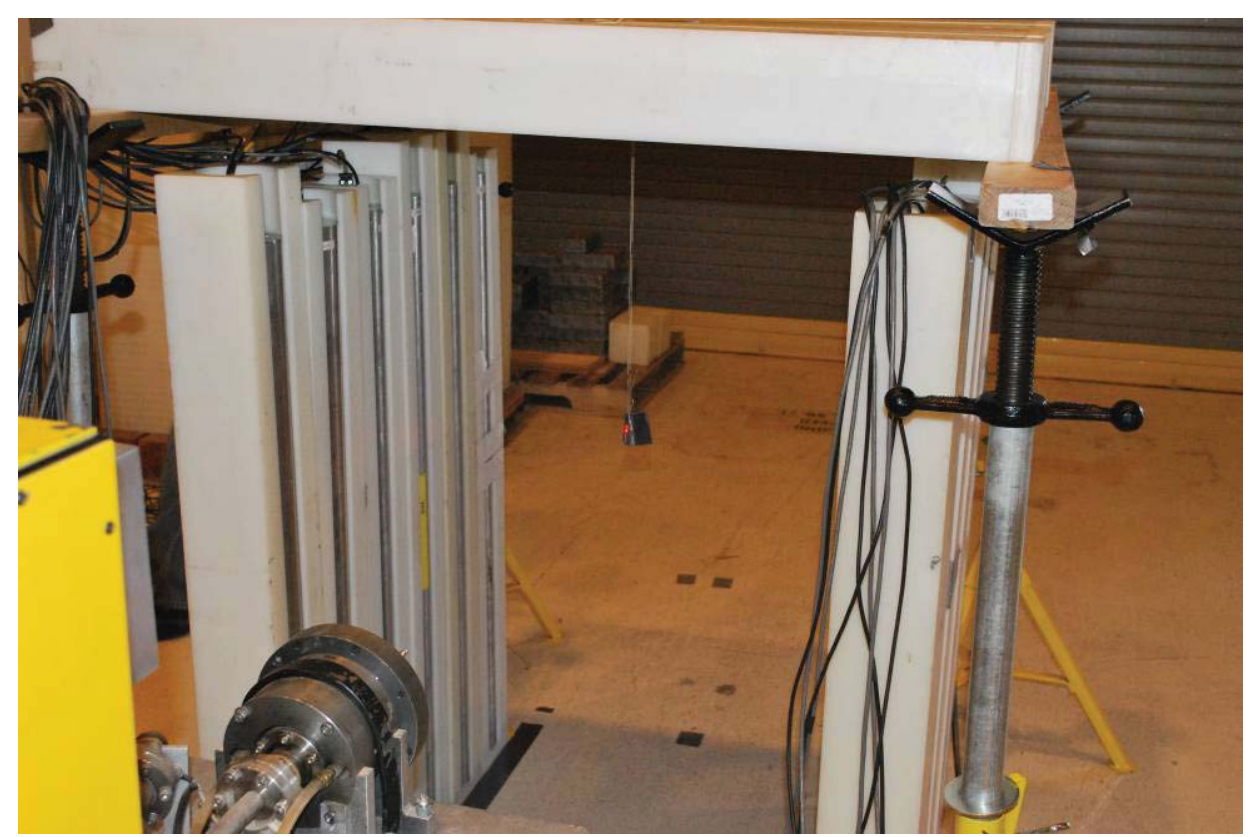

Figure 2-13. Calibration testing with the ${ }^{252} \mathrm{Cf}$ sources. (Note the $1 \mathrm{~m}$ red alignment lasers on the source.)

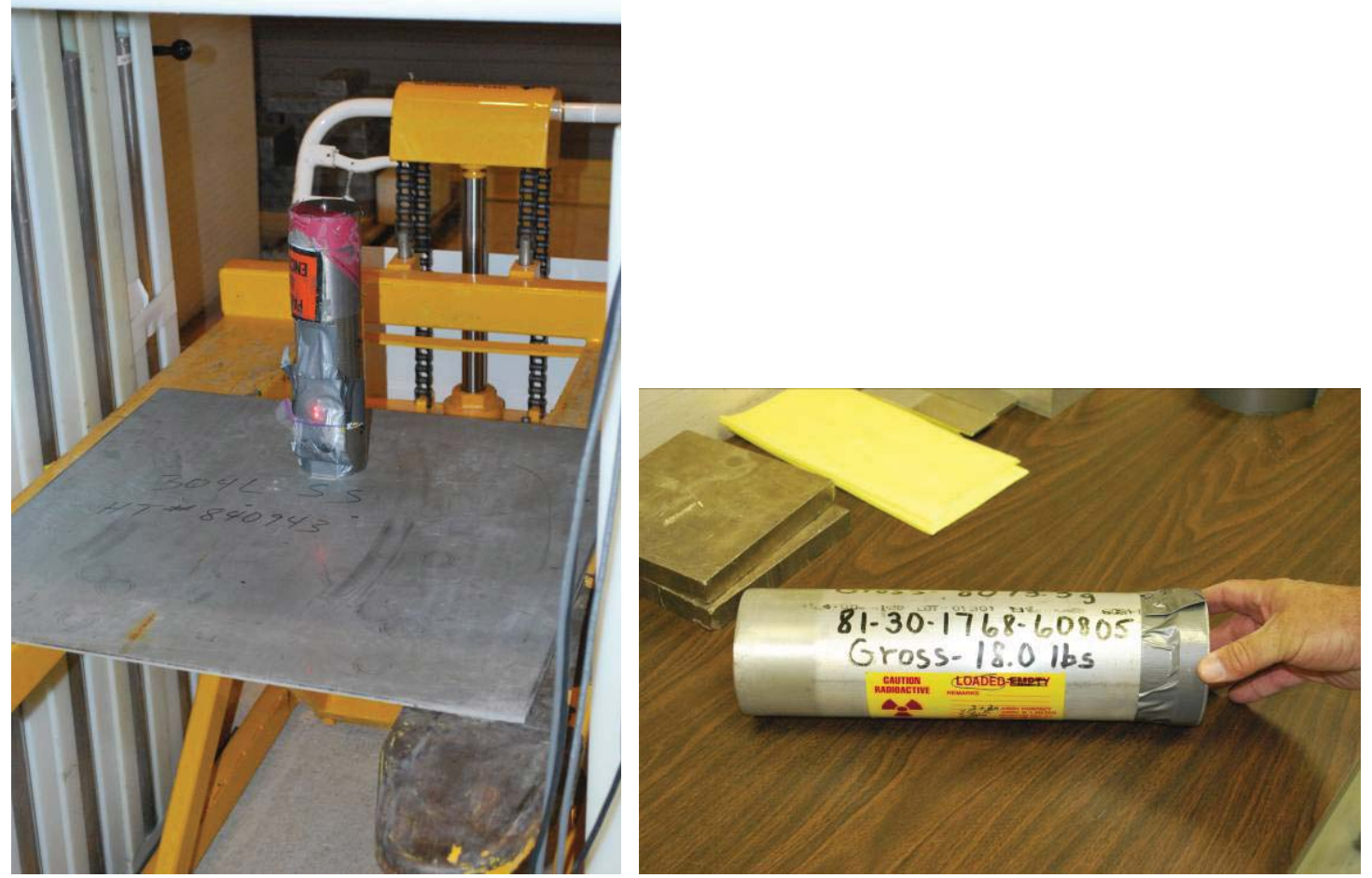

Figure 2-14. The Pu source. (Note $1 \mathrm{~m}$ red alignment lasers on lower housing in left picture).

\subsubsection{Results}

Table 2-2 presents the selective PND results (Singles) from the californium and plutonium source assessments. Note, PND 3 was included in the INL acquisition system after the initial No Source and ${ }^{252} \mathrm{Cf}$ assessments; hence, some detector data were not available in Table 2-2. Note the relatively low and consistent background responses of each detector without any radioactive sources. When sources are 
added, the data show the extent of the center placement of a source via the similarity of the corresponding Left and Right Bank detector responses. Based on the spatial detection response within a detector bank, the $\mathrm{Cf}$ source shows a clear peaking with the top center detector while a broader peak appears to be a result of the unknown location of the Pu source within its relatively larger housing. Also, when comparing the detector (15) responses for these two sources based on the center position of the Top Bank, one can see the effect of the Pu source being only about 1/3 the strength of the total Cf source. Last, if we focus on the outer PND detector (12) in the Right Bank, we can estimate a count rate response of about $20 \mathrm{cts} / \mathrm{s}$ based on: (1) the updated total ${ }^{252} \mathrm{Cf}$ yield which is twice $4.2 \mathrm{E} 4 \mathrm{n} / \mathrm{s}$ (as of 5/08), (2) the reduced ${ }^{252} \mathrm{Cf}$-to-detector (PND 12) distance of $64 \mathrm{~cm}$, (3) the $\sim 3 \mathrm{E}-4 \mathrm{count} / \mathrm{s}$ calibration efficiency [see Section 2.2.1], and (4) the present acquisition time window of 4-8 $\mathrm{ms}$ per trigger pulse. Table 2-2 shows the value for PND 12 to be about $23 \pm 0.5$ counts/s (when corrected for the "No source" background). As with the first campaign ${ }^{252} \mathrm{Cf}$ test, we see good comparisons considering the systematic uncertainties involved in these measurements.

Table 2-3 presents the results from the list-mode acquisition analysis for the Left detector bank, Right detector bank, Top detector bank, and sum of three detector banks. The per-detector, list-mode results are approximately two times bigger than the selective PND results primarily due the larger acquisition window used (that is, $0.5-8$ milliseconds compared to 4-8 for the selective PND results). The counting rate pattern for detectors 1-18 for both $\mathrm{Pu}$ and $\mathrm{Cf}$ is shown in Figure 2-15. The detection patterns are a result of source strengths and actual positioning differences.

Table 2-2. Selective PND results for ${ }^{252} \mathrm{Cf}$ and Pu sources at the nominal 1-m interrogation position using 120-s acquisitions with a 4-ms start acquisition window. (Includes natural background.)

\begin{tabular}{|l|c|c|c|c|c|c|}
\hline \multirow{2}{*}{} & \multicolumn{3}{|c|}{ EDGE Position( Cts/s) } & \multicolumn{3}{c|}{ CENTER position (Cts/s) } \\
\cline { 2 - 7 } & $\operatorname{Left}(6)$ & $\operatorname{Top}(18)$ & $\operatorname{Right}(12)$ & $\operatorname{Left}(3)$ & $\operatorname{Top}(15)$ & $\operatorname{Right}(9)$ \\
\hline $\mathrm{Pu}$ & $6.9 \pm 0.2$ & $7.9 \pm 0.2$ & $7.2 \pm 0.2$ & $15.5 \pm 0.3$ & $13.6 \pm 0.2$ & $17.8 \pm 0.3$ \\
\hline${ }^{252} \mathrm{Cf}$ & $25.8 \pm 0.3$ & $17.8 \pm 0.3$ & $24.2 \pm 0.4$ & - & $44.3 \pm 0.4$ & $27.1 \pm 0.3$ \\
\hline No source & $0.38 \pm 0.06$ & $0.39 \pm 0.05$ & $0.45 \pm 0.06$ & - & $0.22 \pm 0.04$ & $0.38 \pm 0.06$ \\
\hline
\end{tabular}

Table 2-3. List-mode multiplicity results for ${ }^{252} \mathrm{Cf}$ and $\mathrm{Pu}$ source at the nominal $1-\mathrm{m}$ interrogation position using 120-s acquisitions. (Includes natural background.)

\begin{tabular}{|l|c|c|c|c|c|}
\hline \multirow{2}{*}{} & \multicolumn{4}{|c|}{ Singles (Cts/s) } & Doubles (Cts/s) \\
\cline { 2 - 6 } & Left Bank & Right Bank & Top Bank & All & All \\
\hline $\mathrm{Pu}$ & $152.3 \pm 0.6$ & $148.5 \pm 0.5$ & $182.4 \pm 0.6$ & $483.2 \pm 1.0$ & $7.403 \pm 0.469$ \\
\hline${ }^{252} \mathrm{Cf}$ & $436.9 \pm 0.9$ & $444.0 \pm 0.9$ & $389.4 \pm 0.9$ & $1270.3 \pm 1.6$ & $30.43 \pm 0.84$ \\
\hline No source & - & - & - & $17.3 \pm 0.2$ & $0.074 \pm 0.012$ \\
\hline
\end{tabular}




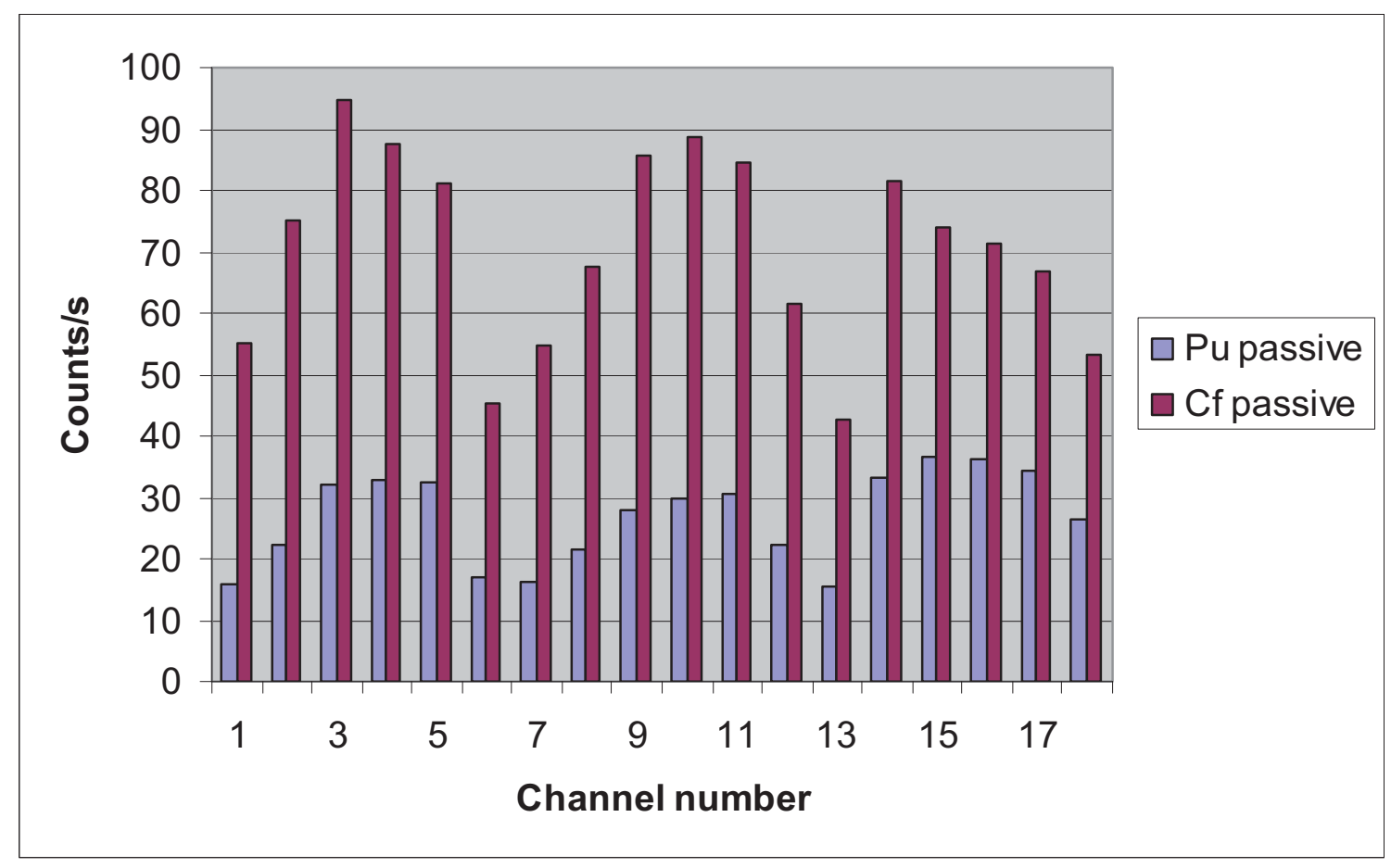

Figure 2-15. Counting rate for each detector with the $\mathrm{Pu}$ and $\mathrm{Cf}$ sources.

To demonstrate repeatability, another assessment focused on DU and HEU with quantities, geometries, and configurations almost identical to the first test campaign assessment. The nuclear materials used in these tests are shown in Figure 2-16 and were positioned on beam axis at $1.1 \mathrm{~m}$ from the photon source. Each nuclear material was attached to a cardboard backing to enable consistent introduction and alignment into various shielding configurations as they were centered on the accelerator beam axis. Each shield configurations consisted of effectively equal thicknesses in front and behind the nuclear material. The shielding studied included $5.1-\mathrm{cm}$ polyethylene (see Figure 2-17) and 2.5-cm thick, $20-\mathrm{cm}$ square bismuth bricks. Using various nominal electron beam energies (i.e.,, 6, 8, and $10 \mathrm{MeV}$ ) and their associated beam currents (that is, $9.5,10.3$, and $3.3 \mu \mathrm{s}$, respectively), Table 2-4 present results for PND 3 (Left Bank, center position) and key list-mode data. It should be noted that if the acquisition windows are matched, the "Poly" case response from the first test campaign $(\sim 0.9 \mathrm{cts} / \mathrm{s})$ compares quite well with the "Poly" case of the second campaign. 


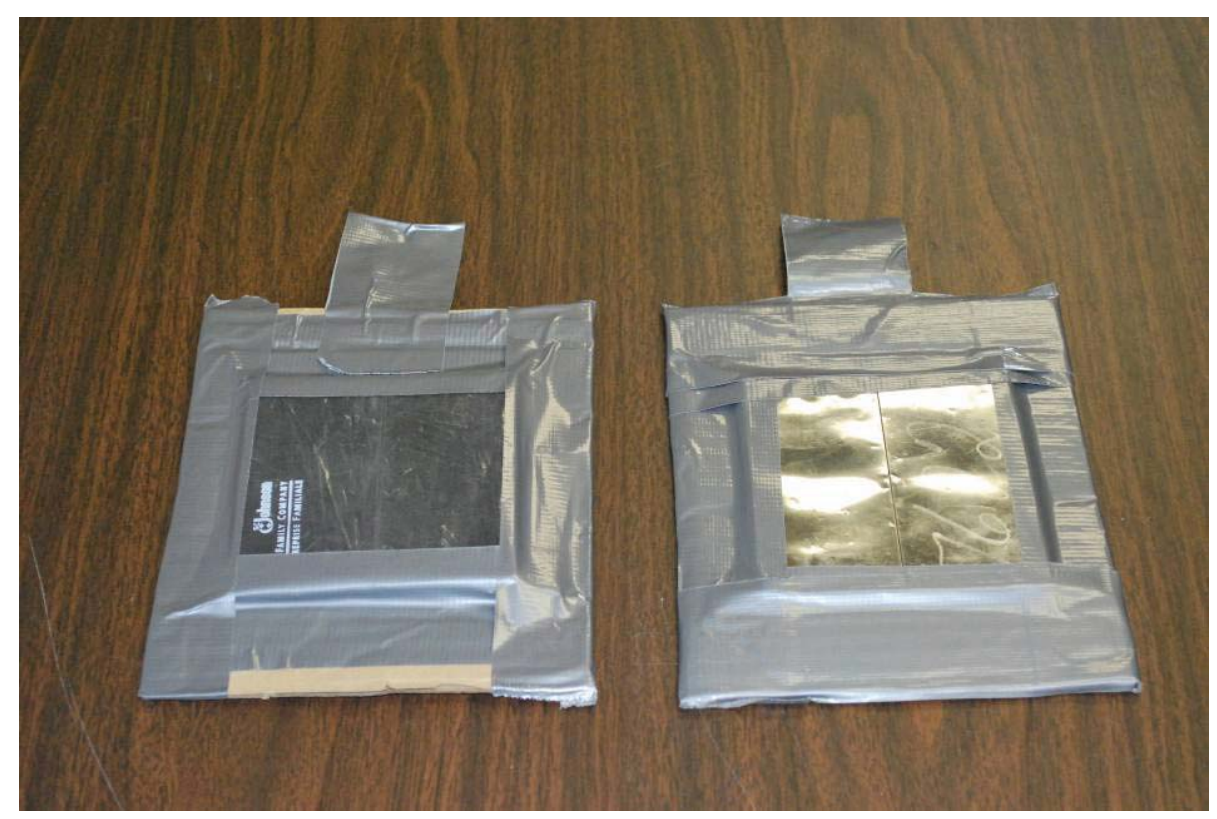

Figure 2-16. DU (left) and HEU (with stainless-steel cladding) used in FY-09 assessments.

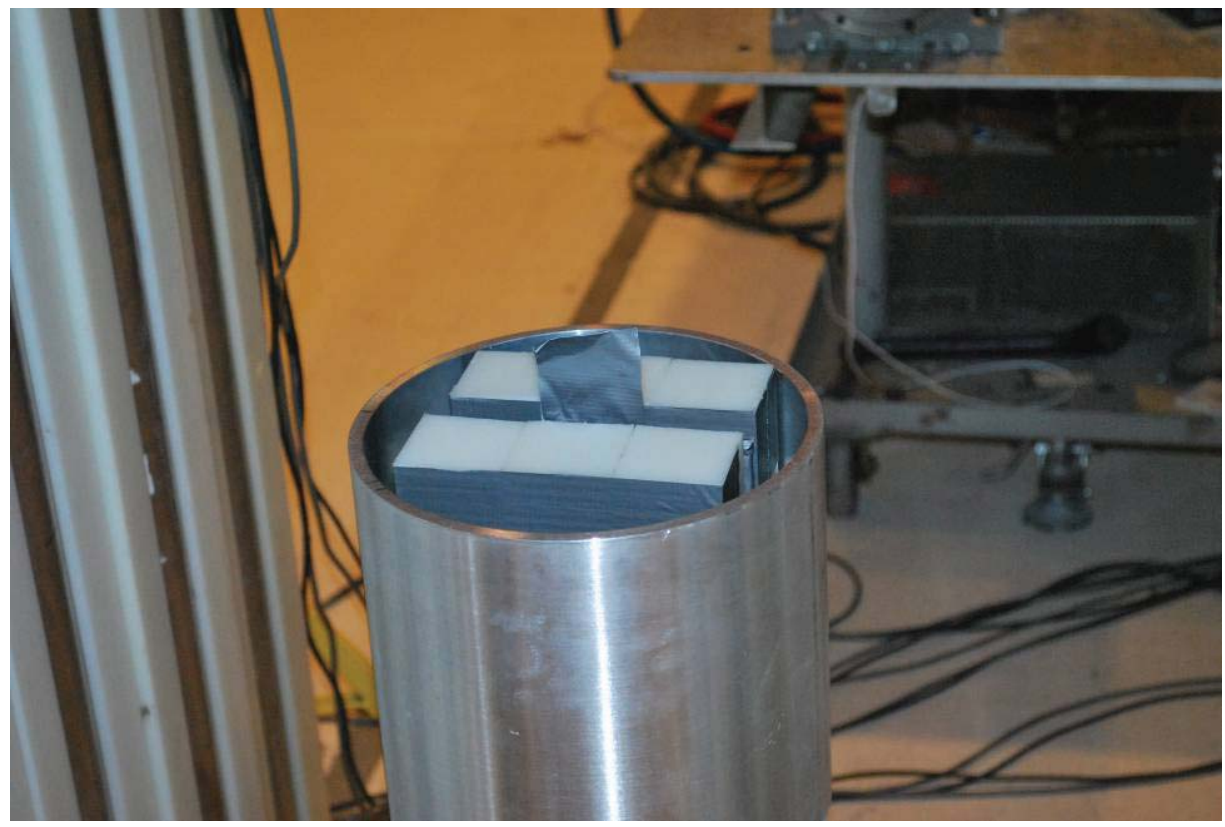

Figure 2-17. A typical shield configuration with the nuclear material positioned at 1.1-m from the photon source. 
Table 2-4. Accelerator ON results at 1-m interrogation position.

\begin{tabular}{|c|c|c|c|c|c|}
\hline \multirow[b]{2}{*}{ Case } & \multirow{2}{*}{$\begin{array}{l}\text { Nominal } \\
\text { Energy } \\
(\mathrm{MeV}) \\
\end{array}$} & \multirow{2}{*}{$\begin{array}{c}\text { INL Singles }^{1} \\
\text { [Det. 3] } \\
(\mathrm{Cts} / \mathrm{s} / \mu \mathrm{A}) \\
\end{array}$} & \multicolumn{3}{|c|}{$\begin{array}{c}\text { List-mode results }{ }^{2} \\
(\mathrm{cts} / \mathrm{s} / \mu \mathrm{A})\end{array}$} \\
\hline & & & Singles & Doubles & $\mathrm{D} / \mathrm{S}$ \\
\hline \multirow[t]{3}{*}{ Poly } & 6 & $0.026 \pm 0.003$ & $1.74 \pm 0.02$ & $0.006 \pm 0.001$ & $0.0035 \pm 0.0007$ \\
\hline & 8 & $0.026 \pm 0.003$ & $2.88 \pm 0.02$ & $0.023 \pm 0.002$ & $0.0081 \pm 0.0007$ \\
\hline & 10 & $0.063 \pm 0.009$ & $10.6 \pm 0.09$ & $0.013 \pm 0.009$ & $0.0120 \pm 0.0008$ \\
\hline \multirow[t]{3}{*}{$\mathrm{HEU}$} & 6 & $0.051 \pm 0.005$ & $2.54 \pm 0.02$ & $0.006 \pm 0.001$ & $0.0025 \pm 0.0005$ \\
\hline & 8 & $2.06 \pm 0.03$ & $77.5 \pm 0.1$ & $0.83 \pm 0.013$ & $0.0107 \pm 0.0002$ \\
\hline & 10 & $7.83 \pm 0.10$ & $275.8 \pm 0.4$ & $4.32 \pm 0.05$ & $0.0157 \pm 0.0002$ \\
\hline \multirow[t]{3}{*}{ HEU w/poly } & 6 & $0.05 \pm 0.005$ & $2.57 \pm 0.02$ & $0.017 \pm 0.002$ & $0.0066 \pm 0.0007$ \\
\hline & 8 & $1.69 \pm 0.03$ & $79.0 \pm 0.1$ & $1.63 \pm 0.02$ & $0.0206 \pm 0.0002$ \\
\hline & 10 & $5.97 \pm 0.07$ & $251.0 \pm 0.4$ & $10.24 \pm 0.08$ & $0.0408 \pm 0.0003$ \\
\hline \multirow[t]{3}{*}{$\mathrm{HEU}$ w/Bi } & 6 & $0.04 \pm 0.004$ & $20.11 \pm 0.06$ & $0.008 \pm 0.001$ & $0.0004 \pm 0.0001$ \\
\hline & 8 & $0.72 \pm 0.02$ & $37.48 \pm 0.09$ & $0.746 \pm 0.012$ & $0.0199 \pm 0.0003$ \\
\hline & 10 & $2.64 \pm 0.06$ & $137.3 \pm 0.3$ & $4.45 \pm 0.05$ & $0.0324 \pm 0.0004$ \\
\hline \multirow[t]{3}{*}{ DU } & 6 & $0.09 \pm 0.006$ & $3.58 \pm 0.03$ & $0.010 \pm 0.001$ & $0.0028 \pm 0.0004$ \\
\hline & 8 & $4.03 \pm 0.04$ & $123.2 \pm 0.2$ & $0.53 \pm 0.01$ & $0.0043 \pm 0.0001$ \\
\hline & 10 & $10.2 \pm 0.11$ & $364.2 \pm 0.5$ & $1.46 \pm 0.03$ & $0.0040 \pm 0.0001$ \\
\hline \multirow[t]{3}{*}{ DU w/poly } & 6 & $0.04 \pm 0.004$ & $2.37 \pm 0.02$ & $0.007 \pm 0.001$ & $0.0028 \pm 0.0005$ \\
\hline & 8 & $1.44 \pm 0.02$ & $56.5 \pm 0.1$ & $0.233 \pm 0.007$ & $0.0041 \pm 0.0001$ \\
\hline & 10 & $4.36 \pm 0.07$ & $179.9 \pm 0.3$ & $1.09 \pm 0.03$ & $0.0061 \pm 0.0001$ \\
\hline \multirow[t]{3}{*}{$\mathrm{DU}$ w/Bi } & 6 & $0.03 \pm 0.004$ & $2.31 \pm 0.02$ & $0.015 \pm 0.002$ & $0.0064 \pm 0.0008$ \\
\hline & 8 & $0.88 \pm 0.02$ & $38.54 \pm 0.09$ & $0.112 \pm 0.005$ & $0.0029 \pm 0.0001$ \\
\hline & 10 & $2.72 \pm 0.06$ & $122.2 \pm 0.3$ & $0.442 \pm 0.016$ & $0.0036 \pm 0.0001$ \\
\hline
\end{tabular}

Figure 2-18 and Figure 2-19 show the Singles and Doubles counting rates from the list-mode data for different material configurations with nominal 8 and $10 \mathrm{MeV}$ electron energies, respectively. (The counting rates for 6-MeV electron energy are very small since this end-point energy just begins to stimulate photonuclear interactions.) As with the 2008 results, these results demonstrate that the coincidence Doubles rate at an early start time $(\sim 500 \mu \mathrm{s})$ is a good indication of neutron multiplication in the item. The Doubles/Singles ratio of these results is clearly different between items having HEU and DU. A threshold on the Doubles/Singles ratio could be used to distinguish between HEU and DU. The distinction is not affected by the presence of high-Z shielding material. In general, the Doubles/Singles ratio is larger with higher electron energies. 


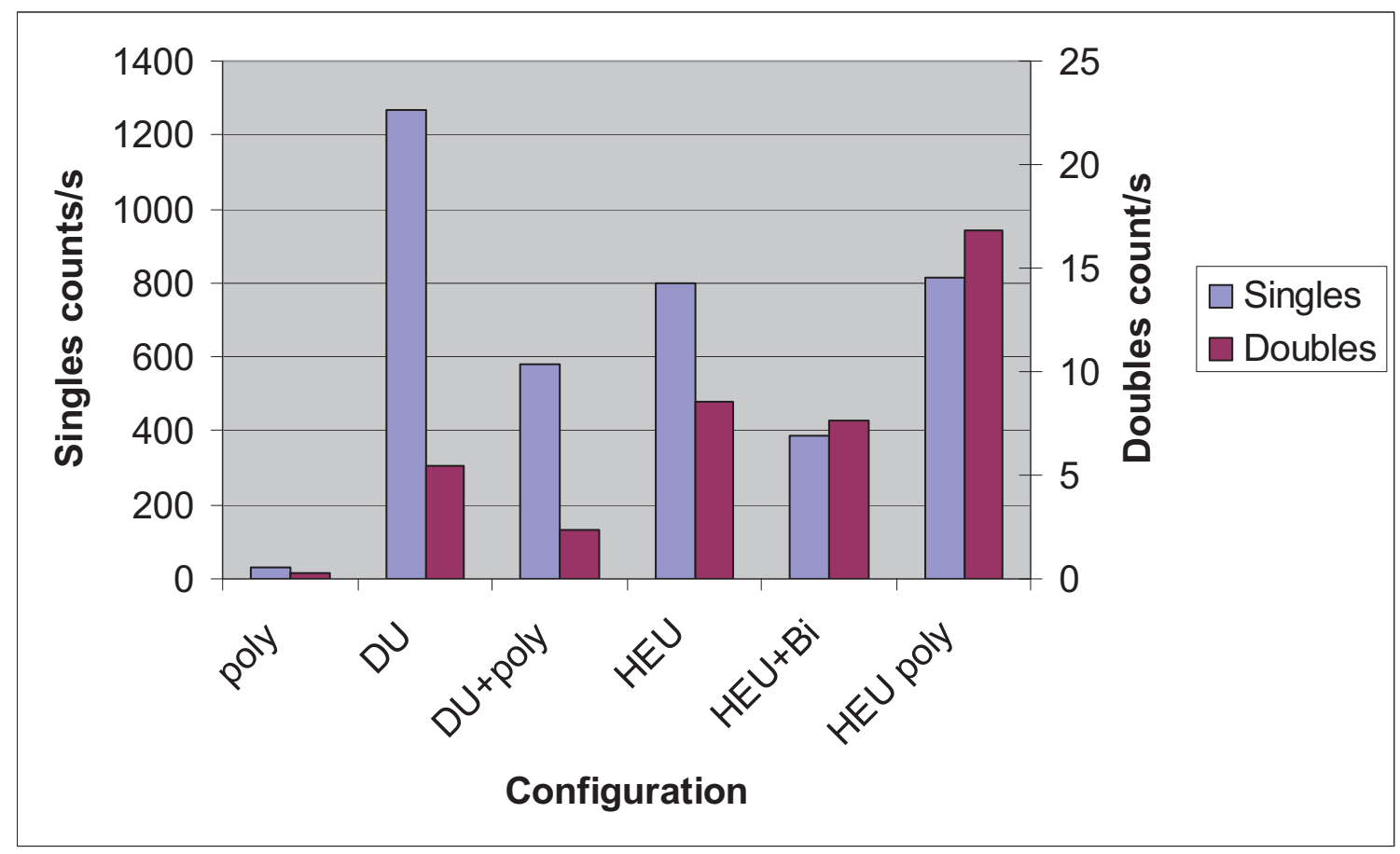

Figure 2-18. Doubles and Singles counting rates from different inspected objects for an 8-MeV electron operation.

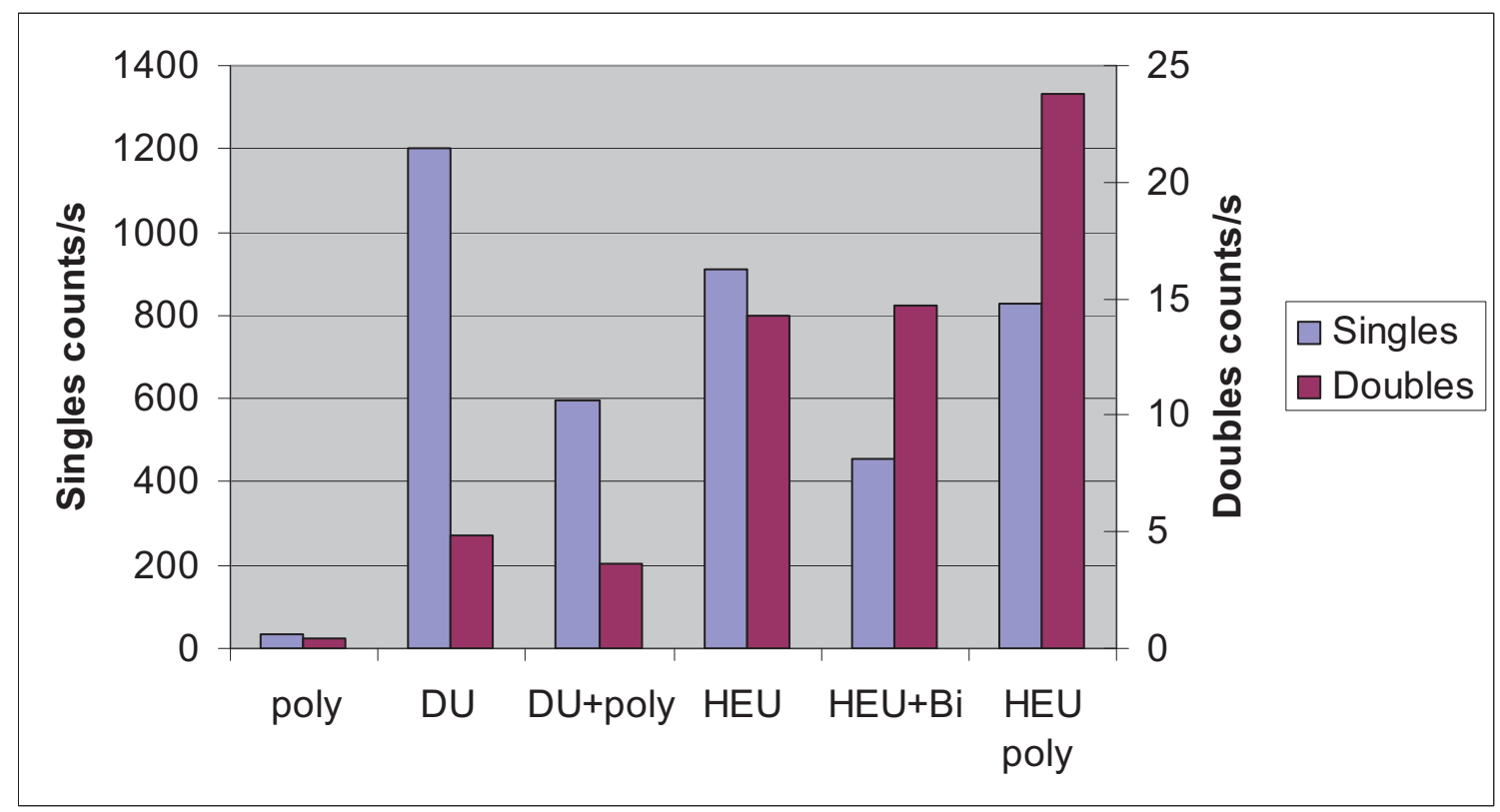

Figure 2-19. Doubles and Singles counting rates from different inspected objects for a 10-MeV electron operation.

Figure 2-20 presents the PND 3 data as a function of electron energy. Note the Singles data become separated with increasing inspection energy when surrounded with polyethylene shielding but not much separation is seen with bismuth. The separation of the polyethylene data is due to the increased number of thermal fissions in the HEU. The response in the high- $Z$ material is due to attenuation effect on the interrogated photon flux and the negligible effect of neutron slowing down within the bismuth shield. 

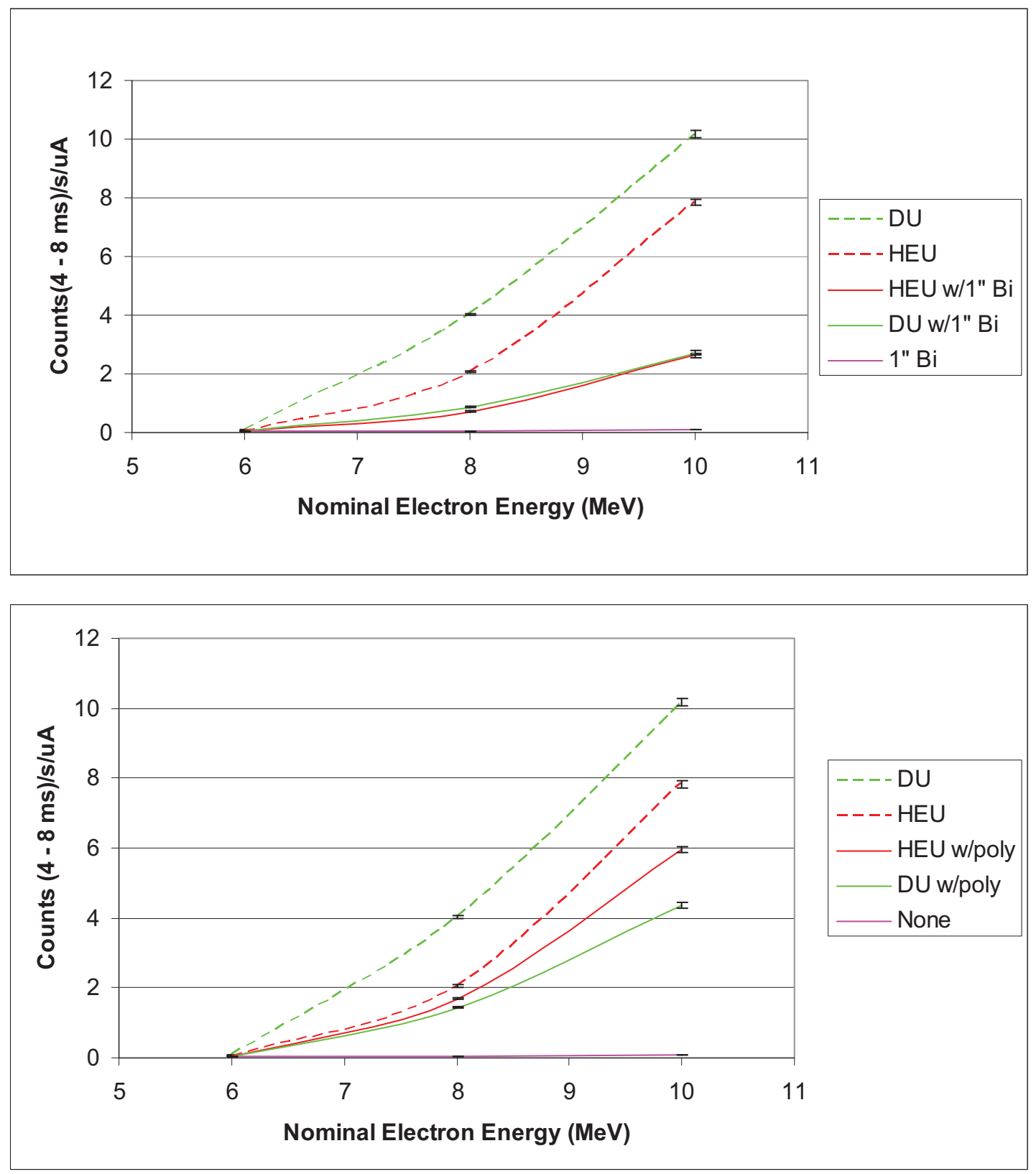

Figure 2-20. Shielded and unshielded HEU and DU results from PND 3 for a 4-8-ms acquisition window.

Figure 2-21, Figure 2-22, and Figure 2-23 show the corresponding list-mode data: Singles, Doubles and Doubles/Singles ratio, respectively, as a function of electron energy. The Doubles and Doubles/Singles ratio show a clear distinction between those cases with HEU (red) and those without (green). 


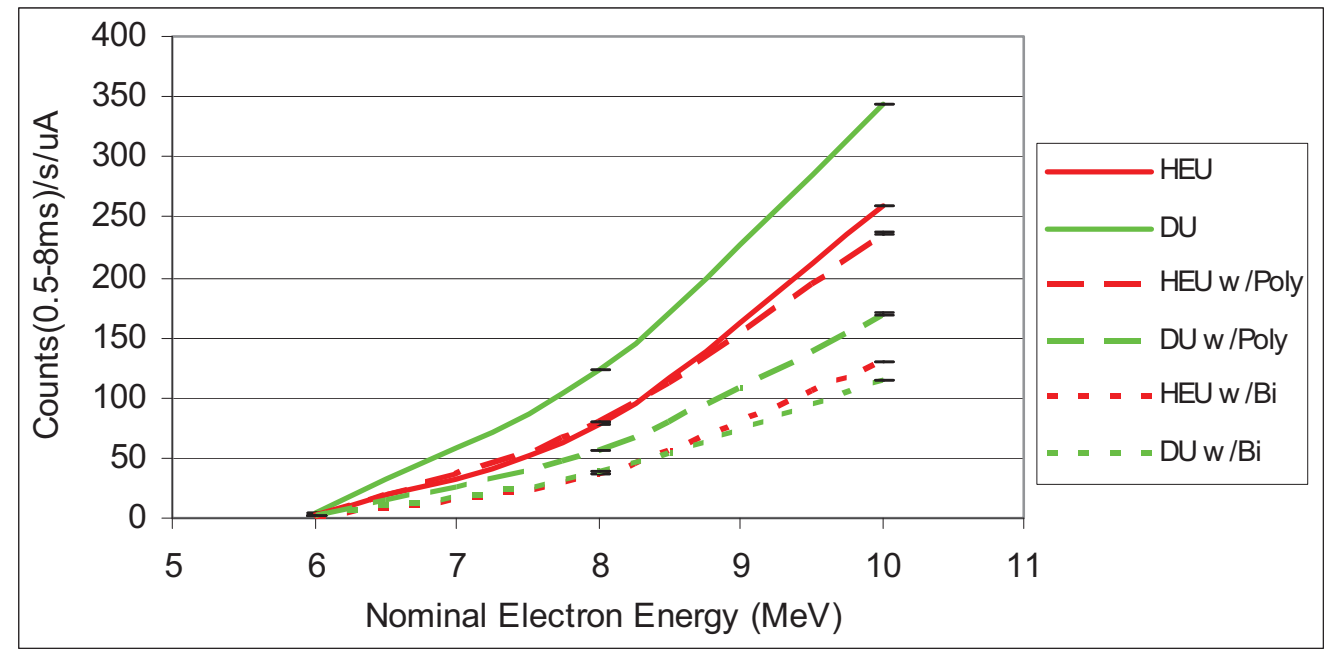

Figure 2-21. Singles count rates for shielded and unshielded HEU and DU results from list-mode data for a 0.5-8 ms acquisition window.

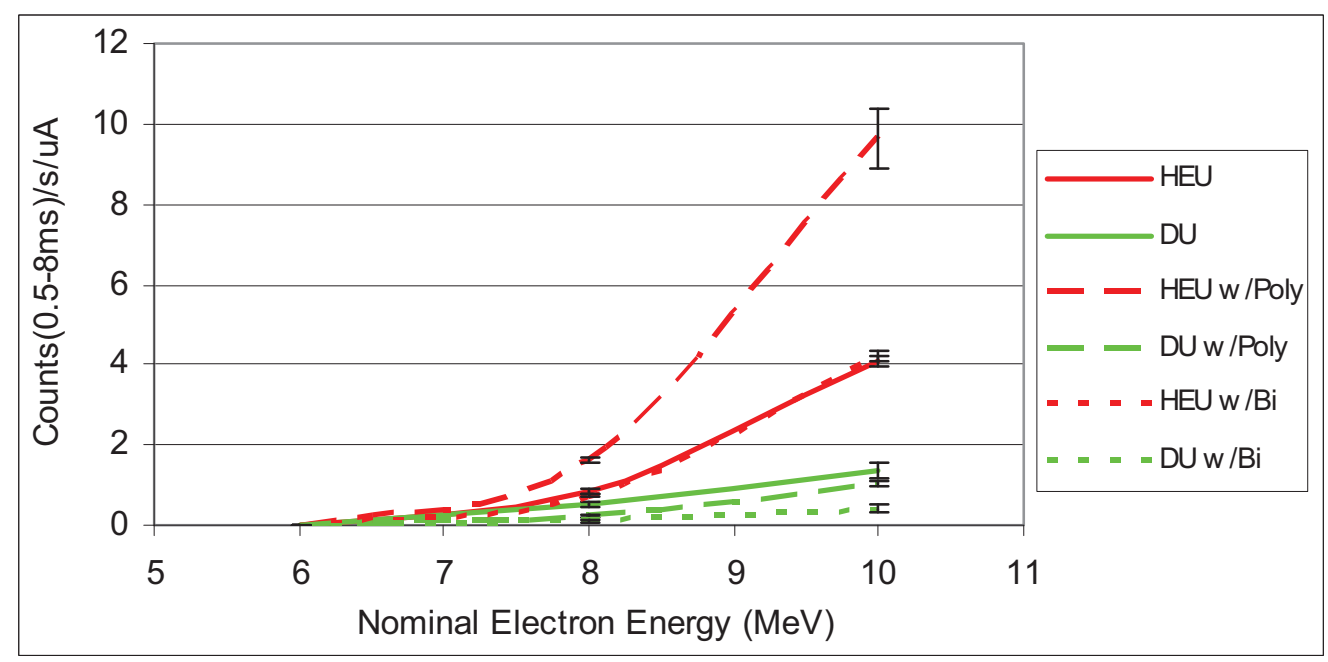

Figure 2-22. Doubles count rates for shielded and unshielded HEU and DU results from list-mode data for a $0.5-8 \mathrm{~ms}$ acquisition window. 


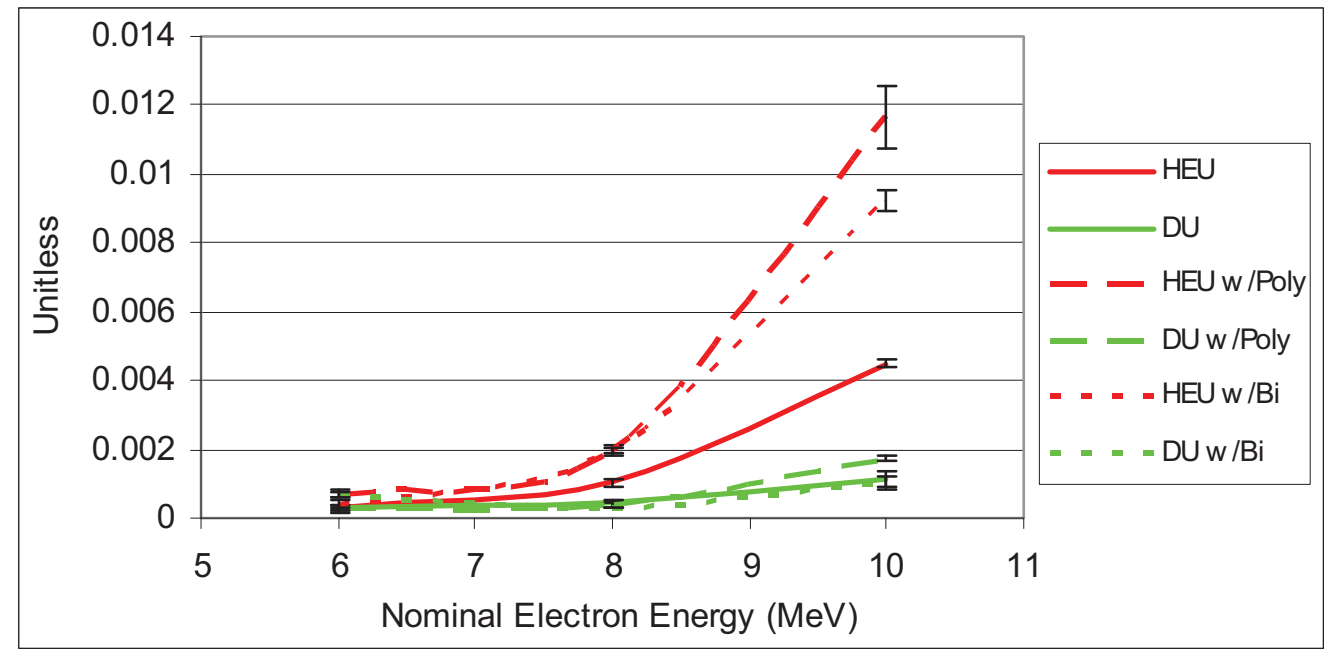

Figure 2-23. Doubles/Singles ratio for shielded and unshielded HEU and DU results from list-mode data for a $0.5-8 \mathrm{~ms}$ acquisition window.

Finally, a $10-\mathrm{MeV}$ electron energy inspection assessment was conducted with varying thicknesses of DU shielding, up to $4.5 \mathrm{~cm}$, in front and back of two HEU plates. The DU, having a $10.2 \times 10.2-\mathrm{cm}$ area, was positioned normal to the beam axis at the nominal 1-m inspection position. The results for PND 3 (Left Bank detectors) are presented in Figure 2-24 while Figure 2-25 shows the maximum DU shield configuration. With the maximum thickness, the removal of the HEU was observed with the PND data. Figure 2-27 shows the list-mode data for this case.

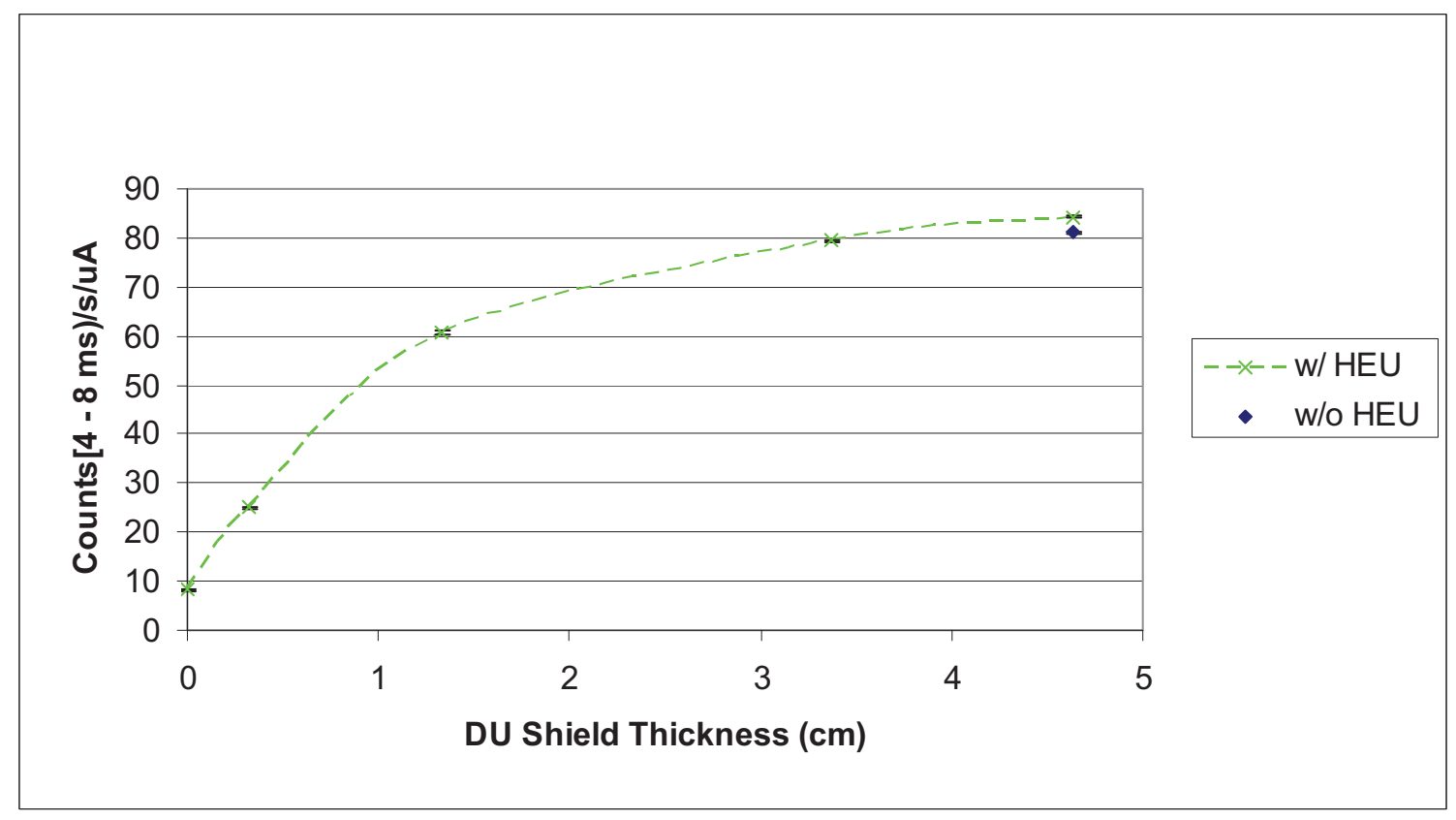

Figure 2-24. PND 3 Singles response for HEU with various thicknesses of DU. 


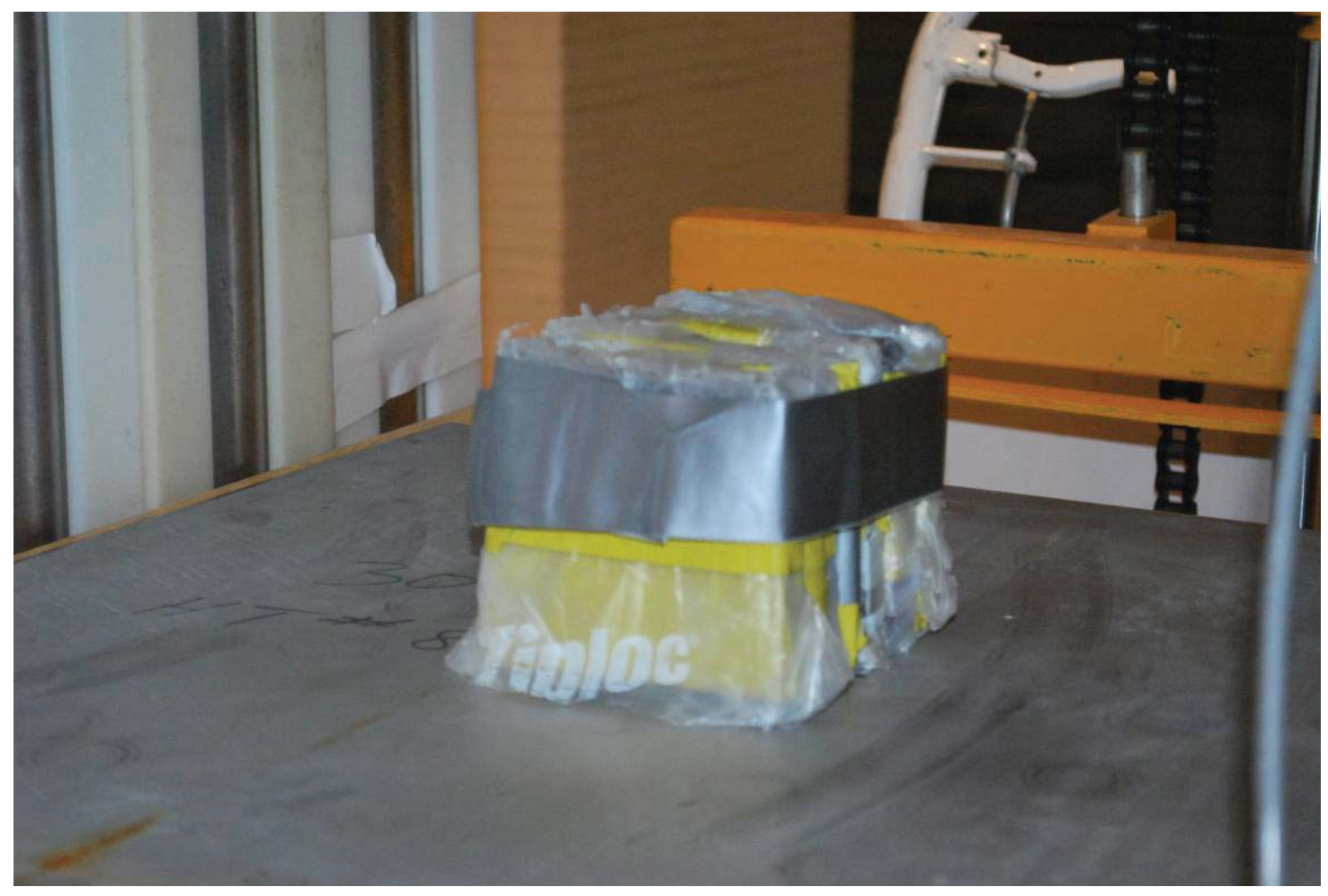

Figure 2-25. Maximum DU shield thickness for the two HEU plates (at nominal 1-m inspection position). The interrogating beam is incident normally on the DU with the accelerator to the left of the observer's position. For each thickness, DU is similarly configured on the front and back.
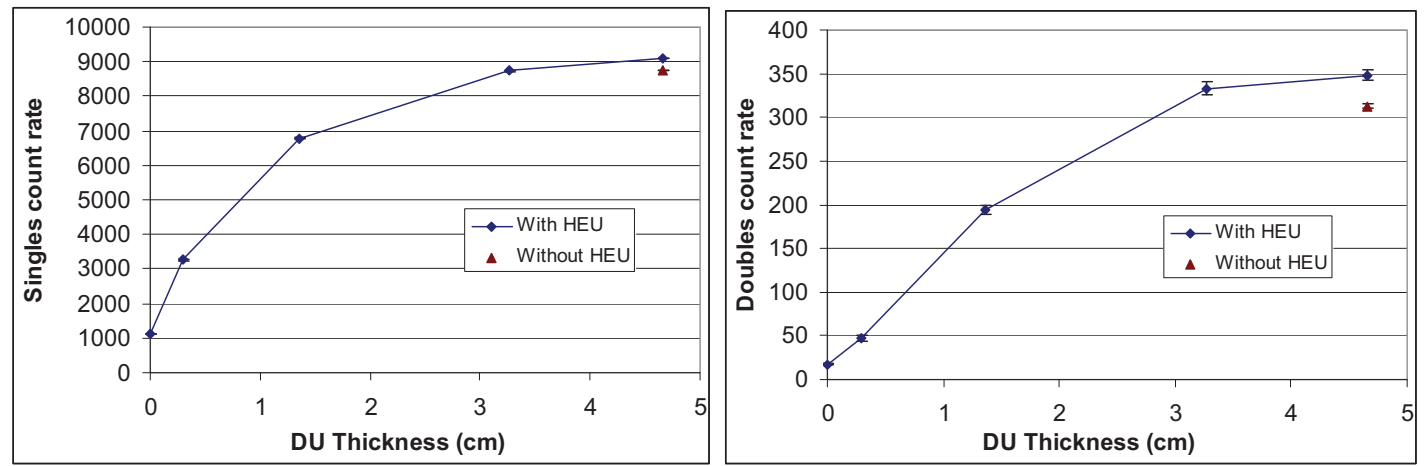

Figure 2-26. List-mode data for HEU with various thicknesses of DU. (Left figure shows Singles. Right figure shows Doubles.)

The behavior of the Singles and Doubles with DU thickness is similar. The effect of removing the HEU from the maximum DU case is relatively larger on the Doubles. Figure 2-27 shows the Doubles/Singles ratio as a function of DU thickness. However, with large amounts of DU, the Doubles/Singles ratio continues to increase; thus, using a simple threshold method for distinguishing between HEU and DU is more complicated. 


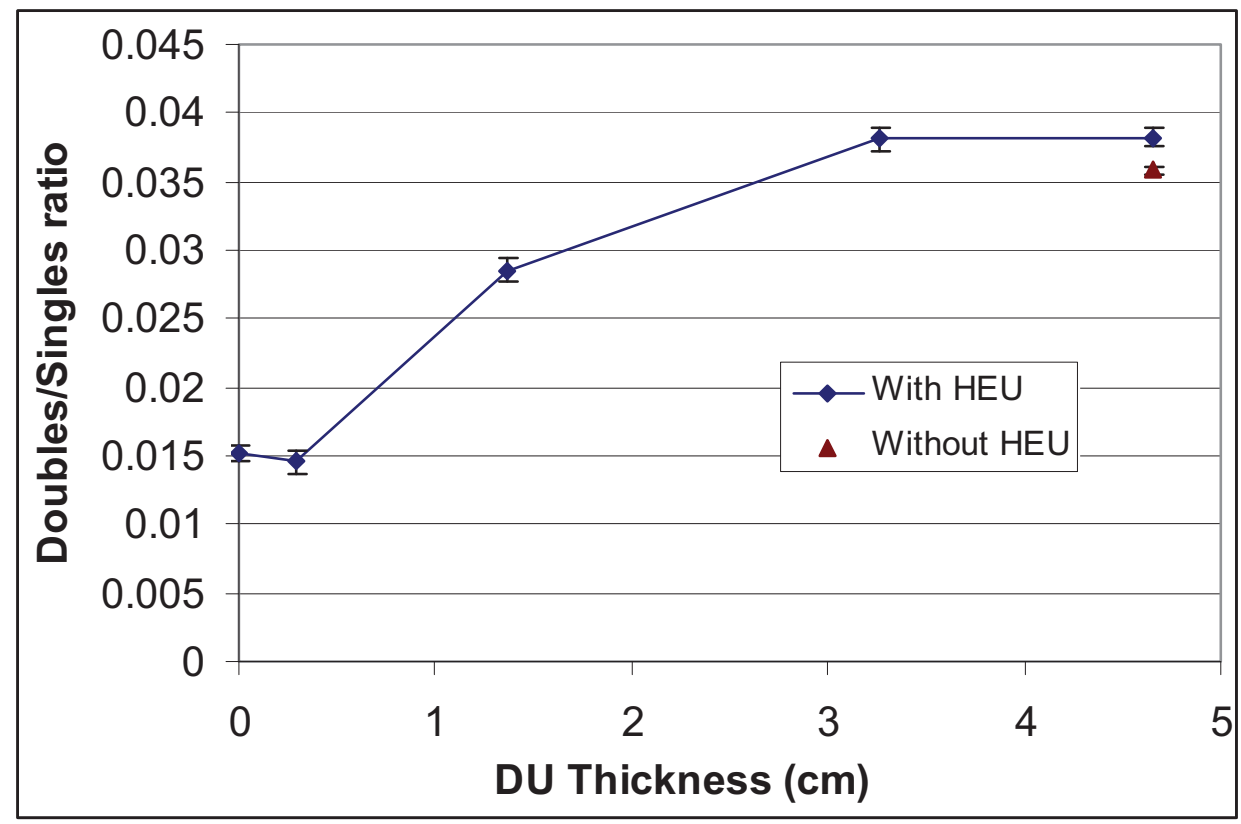

Figure 2-27. Doubles/Singles ratio from list-mode data for HEU with various thicknesses of DU. 


\section{SUMMARY}

These test campaigns have investigated the integration of nuclear material detection and identification using an energetic photonuclear-based nuclear material detection system and a photofission-induced, listmode neutron coincidence counting method between electron pulses of an electron linear accelerator (LINAC). These tests, using up to $10-\mathrm{MeV}$ electron accelerator operations, have demonstrated not only shielded/unshielded nuclear material detection but, more importantly, also appear to indicate a strong ability to enable fissile material identification while essentially being insensitive to non-nuclear materials. The list-mode technique adds additional information, such the Doubles and spatial profile information, that can be used to identify material types or configurations and appears to be able to see correlated data as soon as $\sim 500 \mu$ s after each trigger pulse. A prototype data acquisition system and analysis user interface is available. Applications for this inspection method range from supporting various homeland security missions to treaty-related, weapon dismantlement objectives. Future work recommendations involve assessing LINAC pulse width affects, overall system integration and optimization, improvement to the user interface, performing different nuclear material assessments with application-specific shielding and evaluating if geometry configurations can also be characterized. The results presented here have been obtained experimentally with empirically chosen parameters. A limited amount of modeling work is suggested to underpin and optimize the experimental technique. 


\section{REFERENCES}

1. M. T. Swinhoe, "Experience with List Mode Data Collection for Safeguards." Los Alamos National Laboratory Report LA-UR-07-1858 April 2007.

2. J. L. Jones, et al., "Photofission-based, Nuclear Material Detection: Technology Demonstration," INEEL Formal Report, INEEL/EXT-02-01406, December 2002.

3. J. L. Jones, et al., "Pulsed Photoneutron Interrogation: The GNT Demonstration System," WINCO Formal Report, WINCO-1225, October 1994. 
Appendix A

\section{List-mode Acquisition and Analysis}




\section{Appendix A \\ List-mode Acquisition and Analysis}

The list-mode data are acquired using the program "Notebook Client." The user interface is shown in Figure A-1. A typical measurement is made by collecting ten repetitions, each with duration of 50 seconds. This program is connected with the list-mode module via Ethernet and commands the list-mode module to start taking data and receives the resulting packets of data. It then writes the data to a binary file on the PC hard drive (*.ncd file).

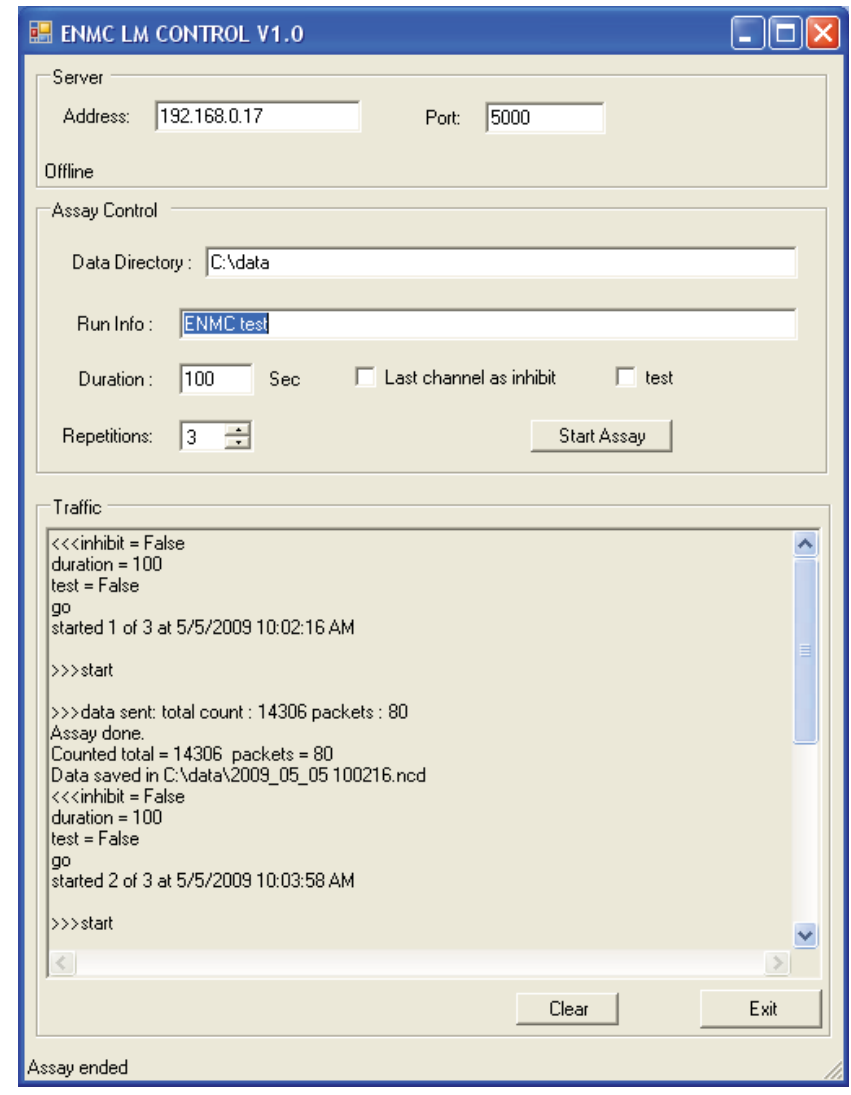

Figure A-1. Data acquisition control screen.

After the data are collected and stored, they can be analyzed with the program LAVA (LANL Active Verification Analysis). The user interface is shown in Figure A-2. LAVA analysis user interface. This allows the analysis parameters to be selected. The Predelay and Gate determine the coincidence counting analysis, which begins an amount of time "window" after the accelerator pulse. The trigger offset is used to align the timing of the recorded accelerator trigger pulse with the actual pulse. (In the particular hardware setup used here, the trigger was recorded as the trailing edge of a very long pulse, leading to an offset of $70 \mu$ seconds). The usual values for all of these parameters are stored as defaults.

The data are analyzed by selecting the relevant group of files and clicking "Go." The files are then read and the resulting Singles and Doubles (with uncertainty) are displayed on the screen. More detailed results are available in comma separated files that are written to the $\mathrm{PC}$ hard drive. In addition to straightforward analysis, the analysis program can give histograms of the count rate following each pulse (Figure A-3a and A-3b) and the macroscopic time variation of the counting rate (Figure A-4). The data can be output in a different format for more detailed analysis. 


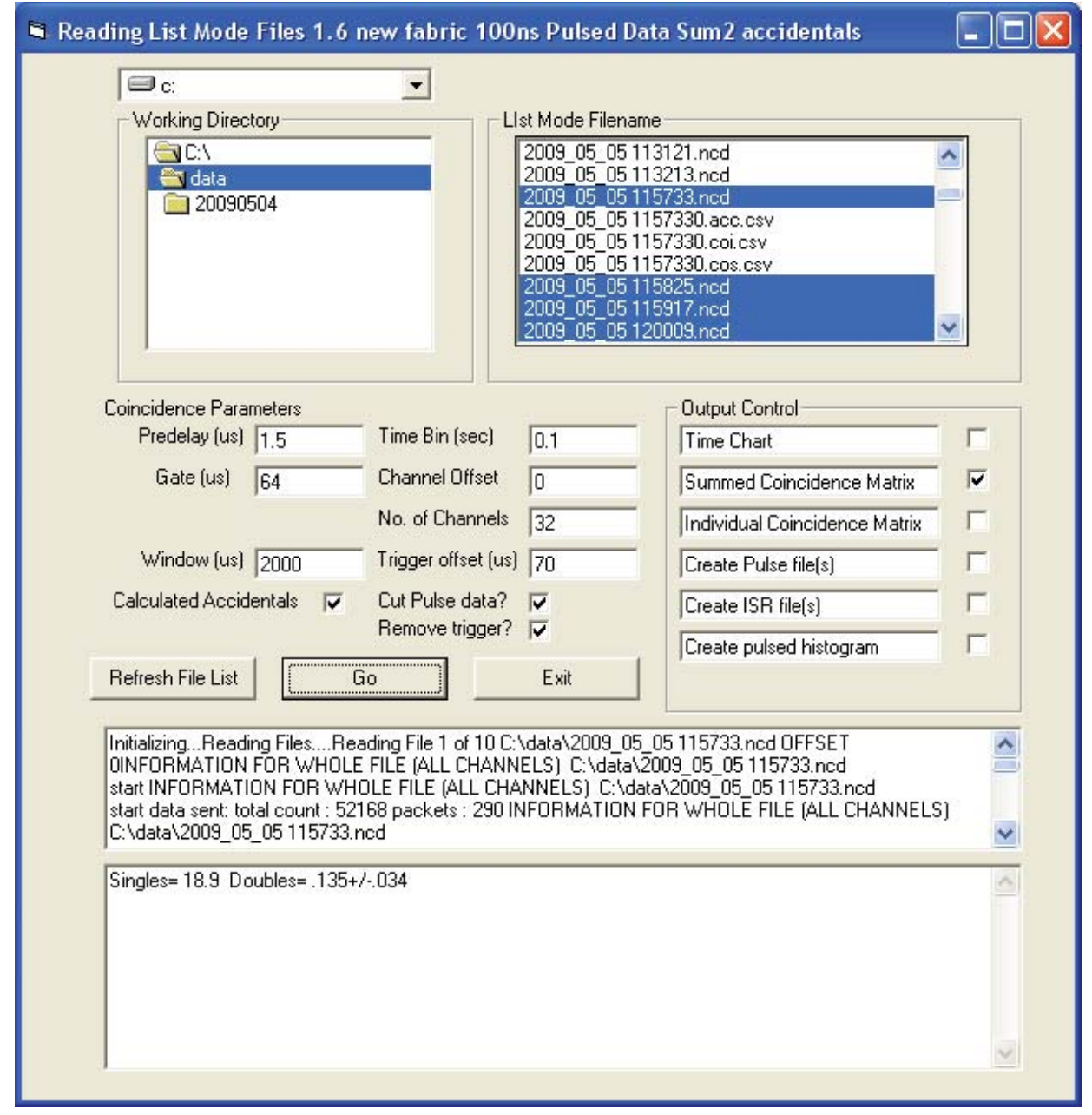

Figure A-2. LAVA analysis user interface.

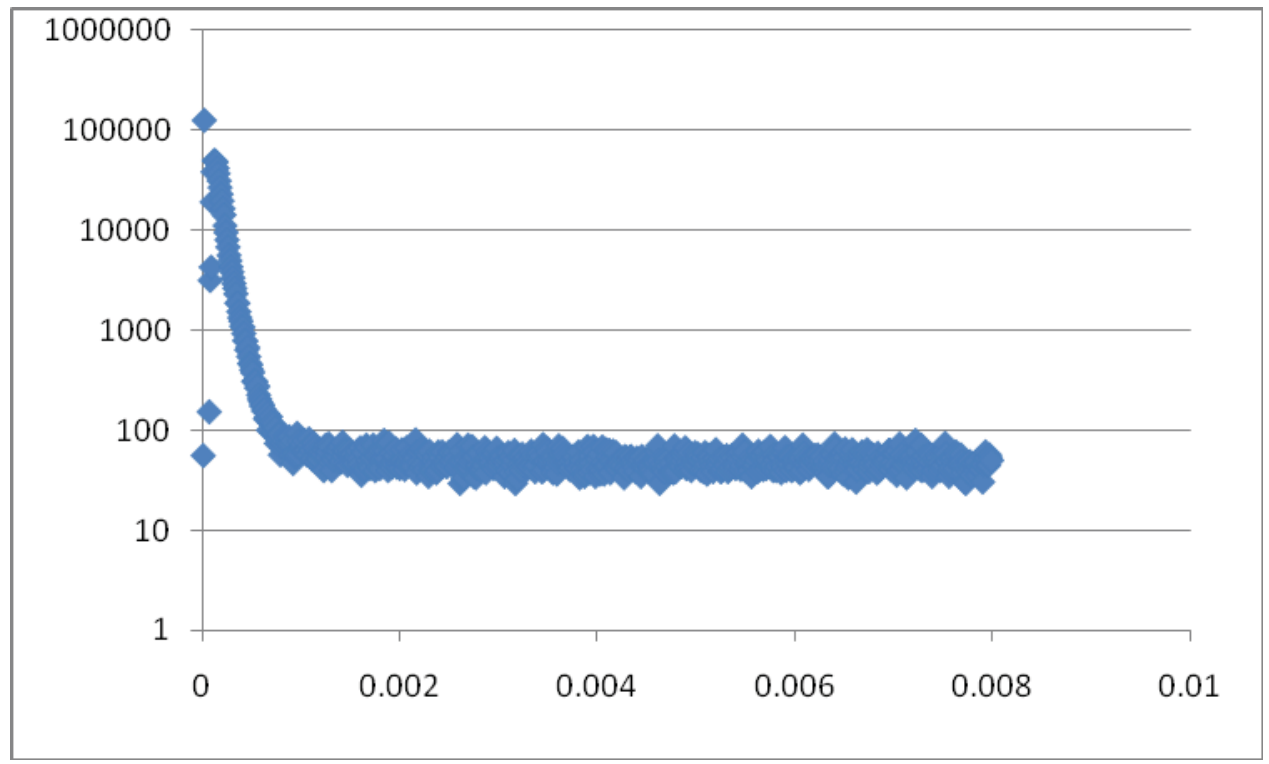

Figure A-3a. Count rate after the accelerator pulse (time in seconds). 


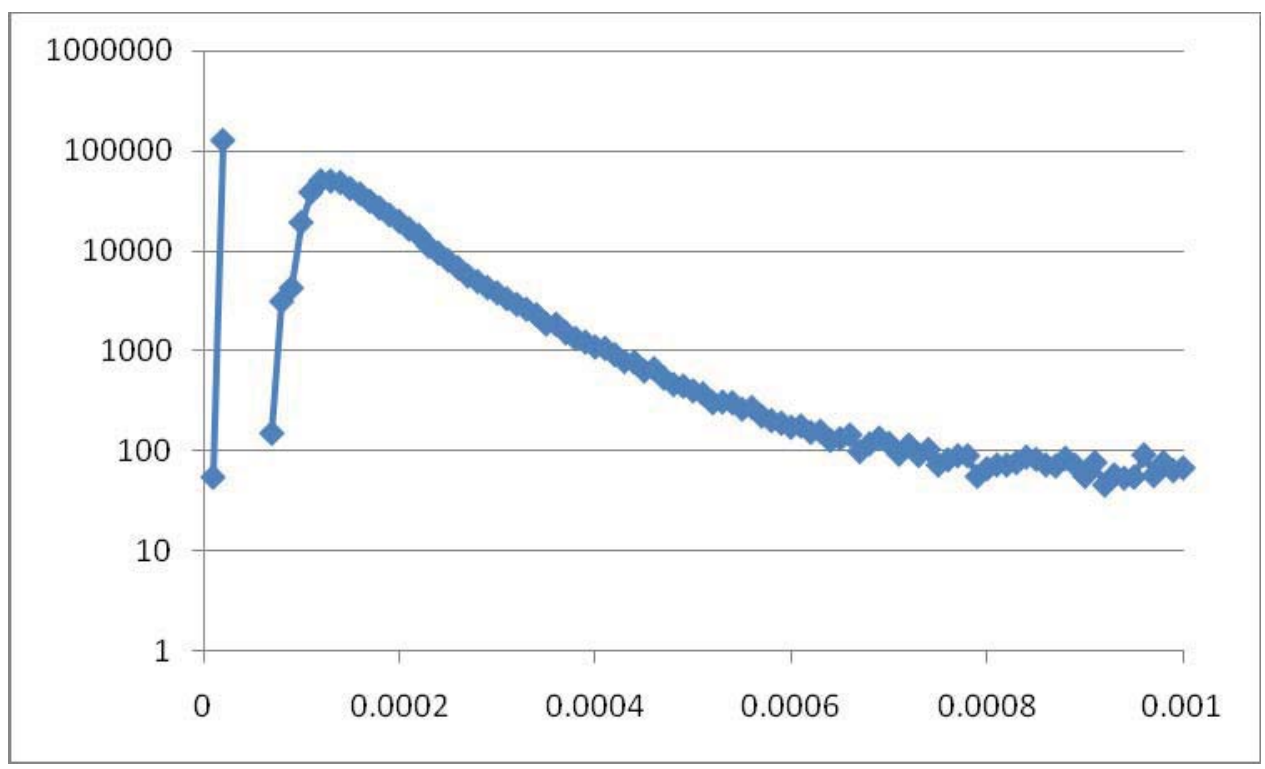

Figure A-3b. Count rate after the accelerator pulse, magnified time scale (time in seconds).

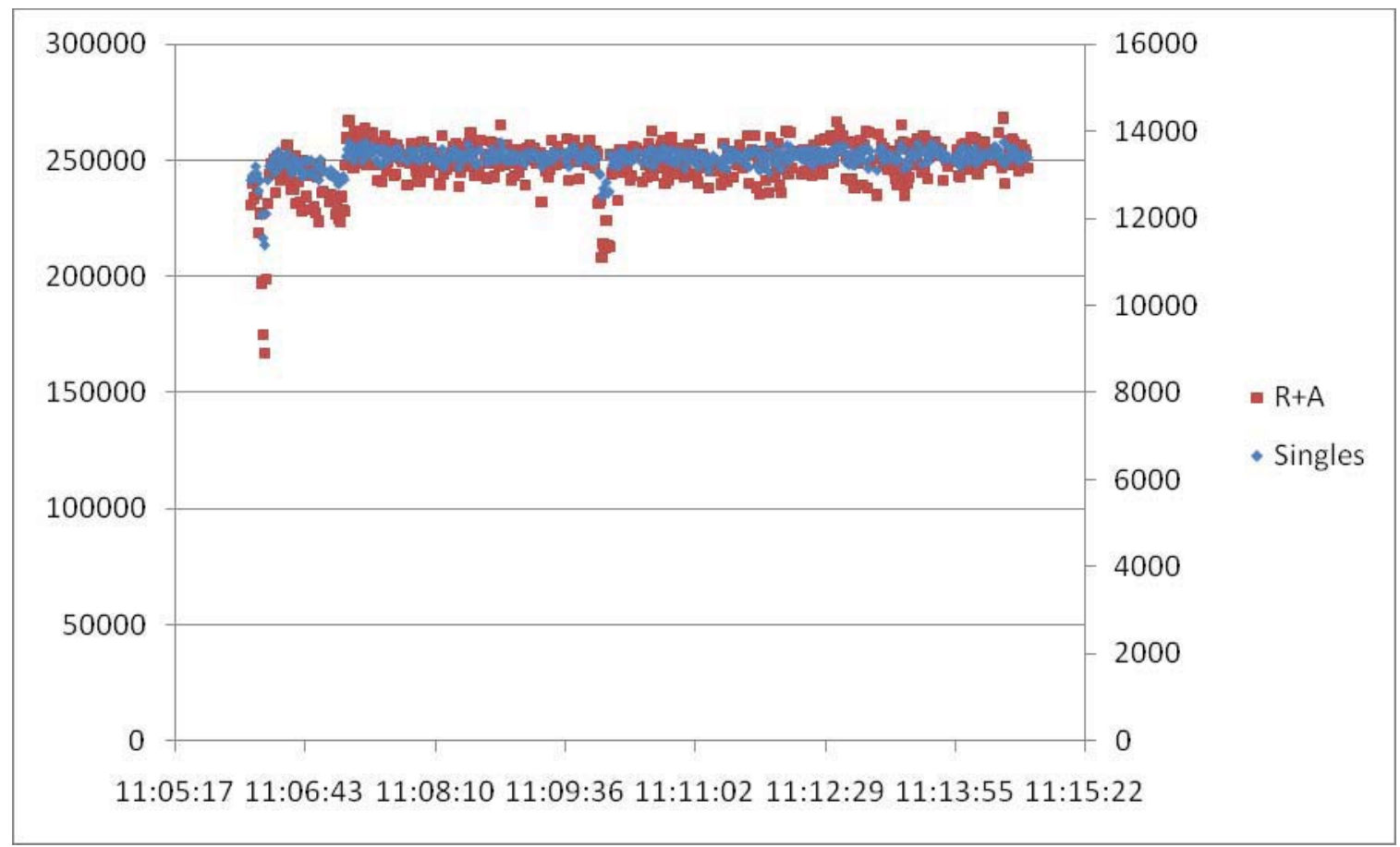

Figure A-4. Count rate as a function of time (over 10 minutes). 